\title{
EL RÉGIMEN JURÍDICO DEL DERECHO FUNDAMENTAL A LA SEGURIDAD SOCIAL EN CHILE: UN ANÁLISIS CRÍTICO DESDE LA PERSPECTIVA DEL DERECHO INTERNACIONAL DE LA PERSONA HUMANA
}

\author{
THE LEGAL REGIME ABOUT THE FUNDAMENTAL RIGHT TO SOCIAL SECURITY IN CHILE: A \\ CRITICAL ANALYSIS FROM AN INTERNATIONAL HUMAN RIGHTS LAW PERSPECTIVE
}

Ivan Obando Camino*

\begin{abstract}
Resumen: El régimen jurídico de la seguridad social chileno tiene una naturaleza mixta, tanto pública como privada, y su gestión la efectúa el Estado y del sector privado. Este régimen jurídico regula el acceso al derecho citado y la cobertura de los distintos riesgos y contingencias sociales en términos teóricamente heterodoxos, empleando para ello mecanismos tanto contributivos como no contributivos. No obstante, un análisis de este régimen, en su dimensión constitucional y legal, a la luz del derecho internacional de la persona humana, sugiere la existencia de déficits normativos que tensionan, si no dificultan, la protección social de las personas y depositan dudas sobre la observancia real de la dignidad de la persona humana, como norma rectora del orden constitucional. En gran medida, el Estado chileno eligió una forma de seguridad social, condicionado en parte por el contexto político y económico, cuyos resultados finales pueden ser inciertos en términos de bienestar colectivo y promoción de los derechos humanos.
\end{abstract}

Palabras clave: Seguridad social. Constitución. Régimen previsional.

\begin{abstract}
The Chilean legal regime about social security has a mixed nature, both public and private, and it is managed by the government and the private sector. This legal regime regulates both the access to the aforementioned right and the coverage of social risks and contingencies based on a heterodox approach from a theoretical perspective, while using for that purpose both contributive and non-contributive mechanisms. However, an analysis of the constitutional and legal dimensions of this regime under the guidance of the international human rights law suggests the existence of legal deficits that stress -if not impede, the social protection of people and cast doubt about the real observance of human dignity as a guiding rule of the constitutional order. To a great extent, the Chilean government chose a form of social security that springs out of both the political context and the economic context, whose final results may be uncertain after considering both the collective good and the promotion of human rights.
\end{abstract}

Keywords: Social security. Constitution. Social security system.

\footnotetext{
" PhD en Ciencia Política por la Universidad Estatal de New York, en Albany; Master of Arts (M. A.) en Ciencia Política por la Universidad Estatal de Nueva York, en Albany; Profesor de Derecho Público y Ciencia Política da Universidad de Talca, Chile; Av Lircay, Talca, VII Región, Chile ; iobandoc@utalca.cla
} 


\section{Introducción}

La seguridad social desempeña un papel fundamental en la obtención de niveles de vida dignos y de un progreso económico saludable en las democracias constitucionales, como lo sostienen los diversos instrumentos jurídicos internacionales, principiando por la Declaración de Filadelfia de 1944, y la experiencia vital de millones de seres humanos, para quienes el acceso y disfrute a ella constituye un derecho fundamental justiciable especialmente ante el Estado.

En el constitucionalismo chileno el derecho fundamental a la seguridad social constituye - formalmente hablando, una institución jurídica de data reciente. Este fue el resultado indirecto de una coyuntura electoral acontecida en 1970 y fue precedida de un proceso de desarrollo infra-constitucional prolongado, el que se basó en la protección a las obras de previsión social acordada por la Constitución Política de 1925 (Obando, 2012, pp. 289-338).

En este proceso jugaron un papel fundamental el particularismo profesional, la política de grupos de presión y el funcionamiento del sistema democrático, lo que generó un sistema de seguridad social multiforme y particularizado que favoreció a los grupos profesionales y laborales urbanos mejor organizados - usualmente de clase media, y sindicalizados, que contaban con apoyo político parlamentario, excluyendo a grandes grupos de trabajadores y habitantes que se encontraban en situación de desigualdad política bajo el régimen democrático (Dahl, 2008, pp. 21 y ss).

El resultado neto fue que el país llegó a contar con más de dos mil leyes de seguridad social, más de un centenar de instituciones relacionadas con ella y a gastar en pensiones más del 18,1\% del Producto Interno Bruto (PIB) hacia fines de la década de 1960 (Arellano, 2012, p. 17), las que favorecían a distintos grupos de presión con regímenes previsionales diversos, existiendo además un fuerte componente no contributivo de cargo estatal, debido a las dificultades de financiamiento de dichos regímenes. Además, el acceso real a las prestaciones respectivas podía ser incierto en muchos casos, debido a los requisitos exigidos por las leyes, disminuyendo aún más la universalidad de aquéllos.

Este problema fue conocido por la elite política de la época, la que decidió en un primer momento concentrar el control de la política laboral, social, económica y previsional en manos del Poder Ejecutivo en 1970, por estimar que resistía mejor que el Parlamento las presiones que surgían del sistema político.

El gobierno autoritario que gobernó Chile entre septiembre de 1973 y marzo de 1990 procedió a una racionalización y reorientación del sistema de seguridad social, motivado por razones económicas y la falta de sustentabilidad del sistema existente. Para ello impuso visión universalista, distinta al particularismo profesional del periodo democrático previo, basada en una lectura neoliberal del principio de subsidiariedad diferente al pensamiento pontificio (Vergara, 1985, pp. 159 y ss).

Esta lectura estableció un Estado subsidiario o mínimo encargado de garantizar los derechos de propiedad - corporales o incorporales, dentro de un marco de ley y orden, para establecer mercados competitivos, en los que pudieren desenvolverse grupos y asociaciones que proyectan la libertad personal (Guardia, 2015, pp. 126, 128). Al decir de Guardia (2015), en el Estado mínimo o subsidiario 
... las políticas sociales son deseables cuando se focalizan en los grupos más vulnerables ... a fin de no entorpecer el sano esfuerzo individual. Queda excluido [sic]. . . la extensión de derechos en la medida que la economía crece y la sociedad civil se organiza, es decir lo que es propio del Estado de bienestar de los países desarrollados (p. 128).

Inspirado por las ideas neoliberales de sus economistas asesores, dicho gobierno procedió a discontinuar los diversos regímenes previsionales previos basados en el reparto, fundamentalmente de vejez, invalidez y sobrevivencia, que administraban servicios públicos de administración autónoma -las antiguas Cajas de Previsión, y a substituirlos por un régimen previsional único y uniforme, basado en la capitalización individual de los afiliados, para lo cual se recurrió a personas privadas con fines de lucro - sociedades comerciales, como instituciones recaudadoras y otorgantes de las prestaciones sociales. Estas sociedades tendrían por giro exclusivo la administración de las cotizaciones de los afiliados y el otorgamiento de las prestaciones respectivas.

El esquema descrito implicó que el financiamiento de los riesgos y contingencias sociales aludidas fue traspasado casi íntegramente a los propios afiliados, a partir de su capacidad de ahorro, incidiendo decisivamente en el desarrollo a largo plazo de un mercado secundario para rentabilizar las inversiones efectuadas por dichas sociedades en beneficio de sus afiliados. Con ello se aseguró indirectamente que las presiones políticas futuras se alejaran del gobierno de turno y, por extensión, del Estado.

Sin embargo, la privatización completa del sistema de seguridad social no fue lograda por dicho gobierno, subsistiendo algunos regímenes previsionales gestionados directamente por el Estado y basados en el reparto. Paradójicamente, este fue el caso del de las Fuerzas Armadas y de Orden y Seguridad Pública, entre otros, debido al riesgo económico que implicaba para sus afiliados pasar a un régimen de capitalización individual. Sin perjuicio de lo anterior, ese gobierno mantuvo un régimen gestionado casi íntegramente por personas privadas y de clara inspiración solidaria, que databa de fines de la década de 1960, como fue el del seguro social de accidentes del trabajo y enfermedades profesionales.

Las circunstancias anotadas se han proyectado hasta el presente y han dotado al país de un régimen jurídico de la seguridad social de carácter mixto, en el cual el Estado asegura constitucionalmente un derecho fundamental a la seguridad social, pero cuya gestión, en términos del otorgamiento de prestaciones sociales, corresponde más a los particulares que al Estado, asumiendo los primeros un papel predominante en materia de vejez, invalidez, sobrevivencia, cesantía, accidentes del trabajo y enfermedades profesionales.

En tal sentido, el nivel de cobertura de riesgos y contingencias sociales efectuado por este régimen jurídico es extenso y variado, empleando para ello tanto mecanismos contributivos como no contributivos, alejándose en términos bastante heterodoxos de los principios teóricos de la seguridad social, lo que ha dado lugar a un régimen jurídico híbrido y que ha tenido un efecto regresivo en el largo plazo en materia de vejez, invalidez y sobrevivencia, pese al crecimiento económico del país desde 1990. Los efectos descritos han sido enfrentados mediante una reforma legal aprobada en 2008, en actual fase de implementación, tendiente a establecer un Sistema Solidario de Vejez e Inva- 
lidez, para las personas de bajos ingresos, carentes de pensión alguna en la materia y cuyo resultado final se verá en los años venideros.

Por otra parte, la incorporación del derecho internacional de la persona humana a la Constitución Política de 1980, en adelante la CPR, acordada en la transición a la democracia, ha llevado indirectamente a una discusión constitucional -en las últimas décadas, sobre cómo ampliar los escasos y limitados derechos económicos, sociales y culturales consagrados en ella bajo la impronta neoliberal y resguardados por una elevada rigidez constitucional.

Este debate no habría sido posible sin la reforma constitucional de la Ley $\mathrm{N}^{\circ} 18.825$, de 1989, que modificó el Art. $5^{\circ}$ Inc. $2^{\circ}$ CPR, generando posturas dispares en la doctrina y la jurisprudencia constitucional. No obstante, este debate parece orientarse últimamente en el sentido de admitir la incorporación de los derechos humanos previstos en tratados internacionales, a todos los derechos asegurados por la CPR, expresa o tácitamente.

Esto último permite cuestionar y problematizar, precisamente, el régimen jurídico del derecho fundamental a la seguridad social chileno, el que presenta grandes déficits normativos a la luz del derecho internacional de la persona humana y que redunda en una tensión o dificultad para la obtención de una protección social apropiada por las personas, pese a las modificaciones introducidas en el pasado reciente. Tales déficits normativos, que se originan en decisiones políticas y económicas relacionadas con el régimen socio-económico instaurado, generan dudas sobre la observancia real del respeto de la dignidad de la persona humana por parte del Estado, proclamado solemnemente por el Art. $1^{\circ}$ Inc. $1^{\circ} \mathrm{CPR}$ y elevado al nivel de norma rectora del orden constitucional por la doctrina y la jurisprudencia.

Este es el objeto de la presente indagación y para estos efectos este trabajo consta de cinco secciones, incluida esta Introducción y la Conclusión. La sección 2. se refiere a la seguridad social en sus aspectos conceptuales y teóricos. La sección 3. analiza el derecho fundamental a la seguridad social en la CPR, considerando los principios constitucionales, la expansión de su contenido normativo mediante la admisión del derecho internacional de la persona humana y la regulación constitucional del derecho respectivo. La sección 4. discurre en términos generales sobre el régimen jurídico de la seguridad social, a partir de un estudio selectivo y crítico de los regímenes previsionales más importantes, para efectos de denotar su fisonomía estructural y determinar sus déficits normativos.

\section{La seguridad social}

La expresión "seguridad social" es de reciente data en las ciencias jurídicas y sociales. Sus orígenes se remontan a la dictación de la Social Security Act estadounidense, en 1935 y a la publicación del Informe Beveridge británico, en 1942, los que contribuyeron a su difusión a nivel mundial, especialmente tras la Declaración de Filadelfia, de 1944.

Esta denominación sugiere que los riesgos y contingencias sociales pueden afectar a la totalidad o parte de la población de un país, independientemente de su condición laboral, edad, estado civil o nacionalidad, entre otros, por lo que toda la sociedad debe responder a aquéllas. Esto obedece 
al imperativo - jurídico y político, por el goce de una vida digna para todos, el que se encuentra en actualización constante conforme emergen nuevas nociones sobre desarrollo político y social (Novoa, 1977, pp. 9 y ss; Humeres, 2005, p. 23).

Precisamente, los riesgos y contingencias sociales plantean a la sociedad contemporánea desafíos respecto del goce de una vida digna. Según Lanata (2001), los riesgos sociales tradicionalmente dijeron relación con hechos futuros, involuntarios y dañosos que se traducían usualmente en una pérdida patrimonial cuasi-inmediata para las personas, como la muerte, invalidez y enfermedad; en cambio, las contingencias sociales se referían a hechos futuros de menor entidad, no siempre involuntarios y que generaban una carga patrimonial, como la maternidad y crianza de hijos, entre otros (pp. 1 y ss). En tal sentido, unos y otros acontecen durante la vida de las personas y tienen consecuencias que impactan no sólo a los directamente afectados, sino a toda la sociedad en general, la que debe hacerse cargo de ellos (Lanata, 2001, pp. 1 y ss).

Esta amplitud de la cobertura de la seguridad social persuadió, precisamente, a la Comisión de Expertos que redactó el Informe sobre la reforma de la Seguridad Social chilena, de 1964, a concebirla como ". . . la rama de la política socio-económica de un país, por la cual la comunidad protege a sus miembros, asegurándoles condiciones de vida, salud y trabajo socialmente suficientes, a fin de lograr mejor productividad, más progreso y mayor bienestar comunes" (Humeres, 2005, p. 13). Más recientemente, la Organización Internacional del Trabajo, en adelante la OIT, ha conceptualizado la seguridad social como

... la protección que la sociedad proporciona a sus miembros mediante una serie de medidas públicas, contra las privaciones económicas y sociales que de otra manera derivarían de la desaparición o de una fuerte reducción de sus ingresos como consecuencia de enfermedad, maternidad, accidente del trabajo o enfermedad profesional, desempleo, invalidez, vejez y muerte; y también la protección en forma de asistencia médica y de ayuda a las familias con sus hijos (Plataforma Interamericana de Derechos Humanos, Democracia y Desarrollo, 2003, p. 12).

En los términos planteados, la seguridad social dice relación con múltiples contingencias sociales y se traduce en prestaciones sociales, para cuyo otorgamiento juegan un papel fundamental el Estado y la sociedad.

Sin embargo, la seguridad social genera efectos más allá de la experiencia individual de las personas, los que se dejan sentir en todo el sistema político. Así lo reconoció la OIT en su Resolución Relativa a la Seguridad Social, adoptada en su Conferencia N 89, de 2001, en adelante la Resolución, cuya Conclusión 2. señaló que

.. la seguridad social es muy importante para el bienestar de los trabajadores, de sus familias y de toda la sociedad. Es. . . un instrumento de cohesión social, y de ese modo contribuye a garantizar la paz social y la integración social. Forma parte indispensable de la política social de los gobiernos y es una herramienta importante para evitar y aliviar la pobreza. A través de la solidaridad nacional y la distribución justa de la carga, puede contribuir a la dignidad humana, a la equidad y a la justicia social. También es importante para la integración política, la participación de los ciudadanos y el desarrollo de la democracia (Constitución, convenios, resoluciones y recomendaciones de la Organización Internacional del Trabajo, Resolución Relativa a la Seguridad Social, 2001, pp. 1 y ss.). 
En tal sentido, Humeres (2005, p. 22 y ss) sostiene que la seguridad social comprende, a lo menos, los seguros sociales, por medio de los cuales se otorgan prestaciones médicas y pecuniarias; la asistencia social, que cubre las contingencias sociales desatendidas por los seguros sociales o atendidas insuficientemente; $y$, las prestaciones sociales, que son prestaciones otorgadas directamente para proteger el grupo familiar. El Convenio sobre la Seguridad Social N 102, de 1952, de la OIT, dicta normas mínimas aplicables a la asistencia médica; prestaciones monetarias de enfermedad; prestaciones de desempleo; prestaciones de vejez; prestaciones en caso de accidente del trabajo y enfermedad profesional; prestaciones familiares; prestaciones de maternidad; prestaciones de invalidez y prestaciones de sobrevivientes. En tanto, la Observación General N 19, de 2007, del Comité de Derechos Económicos, Sociales y Culturales del Consejo Económico y Social, en adelante la Observación General, expresa que el derecho a la seguridad social persigue otorgar protección, en particular, en contra de la falta de ingresos procedentes del trabajo debido a enfermedad, invalidez, maternidad, accidente laboral, vejez o muerte de un familiar; gastos excesivos de atención de salud; apoyo familiar insuficiente, en particular para los hijos y los familiares a cargo (Comité de Derechos Económicos, Sociales y Culturales, 2008, p. 2).

Por lo expuesto, la seguridad social constituye un fenómeno multidimensional, pues su concepto varía de acuerdo a la dimensión analizada, a saber, orgánica, funcional, normativa o institucional. Así, orgánicamente, ella alude a aquellos órganos, sean o no estatales, que intervienen en la prevención y satisfacción de los diversos riesgos y contingencias sociales, mientras que funcionalmente es el conjunto de actividades emprendidas para prevenir y satisfacer aquéllos, por parte de los órganos mencionados. En tanto, cuando ella es entendida en términos jurídicos, se alude a las normas jurídicas y sus principios interpretativos, sea que constituyan o no un sistema, que establecen directivas para la prevención y satisfacción de riesgos y contingencias sociales, en términos de mandatos, deberes derechos y sanciones. Finalmente, en términos institucionales, la seguridad social es el patrón continuo, estable y regular de acciones por las que una sociedad responde una sociedad a la presencia y ocurrencia de riesgos y contingencias sociales (Novoa, 1977, pp. 44 y ss).

En la doctrina especializada existe consenso en que la seguridad social tiene como marco de referencia un conjunto de principios rectores que permiten reconocer su identidad disciplinaria, presiden su aplicación en la esfera de interferencia intersubjetiva y aseguran la eficacia de las directivas y normas relativas a ella.

Más allá de la naturaleza política o meramente instrumental de algunos de ellos, su consideración conjunta permite avanzar hacia el establecimiento de un sistema de seguridad social -o de protección social en términos más contemporáneos, por parte de los gobiernos, pese a que su concreción específica puede ser contingente y gradual. Según Novoa (1977, pp. 83-118), Humeres (2005, pp. 35-38), Bowen (1974, pp. 116-119) y Grzetich (2005, pp. 25-56), estos principios rectores son los siguientes: universalidad objetiva; universalidad subjetiva; integridad o suficiencia; unidad; solidaridad; internacionalidad; igualdad; participación; protector, y exclusividad legal.

Basándonos en estos autores, podemos concebir estos principios de la manera siguiente: 
a) Universalidad objetiva: la seguridad social debe extenderse a todas las contingencias sociales de carácter no voluntario, comprendiendo en etapas más avanzadas las que afectan lo social, económico y cultural;

b) Universalidad subjetiva: la seguridad social debe comprender sobre una base no discriminatoria a toda la población, independientemente de sus circunstancias personales;

c) Integridad o suficiencia: la seguridad social debe otorgar prestaciones o beneficios que satisfagan totalmente las consecuencias directas de una contingencia social determinada;

d) Unidad: la seguridad social debe desplegarse en forma sistémica, unitaria y estructurada, como una política pública coordinada, integral, uniforme y de conjunto;

e) Solidaridad: la seguridad social tiene una finalidad redistributiva, ya que todas las personas contribuyen a sus objetivos conforme a sus posibilidades y se benefician de ella de acuerdo a sus necesidades;

f) Internacionalidad: la seguridad social vincula jurídicamente sus instituciones a un marco cuya fuente son los convenios de la OIT, a los que deben agregarse los instrumentos jurídicos internacionales del sistema internacional de protección de derechos humanos, referidos infra;

g) Igualdad: por una parte, la seguridad social debe proporcionar prestaciones iguales ante contingencias sociales idénticas a las personas (igualdad no sustancial); por la otra, la seguridad social debe proporcionar prestaciones iguales o uniformes en su monto, sin consideración a la contingencia social de que se trate y el beneficiario (igualdad sustancial);

h) Participación: la seguridad social debe reconocer la intervención de sus beneficiarios en su gestión, en grado variable, como contrapartida de las obligaciones financieras que pesan sobre estos últimos;

i) Protector: la seguridad social tiene una finalidad tutelar y garantista de la dignidad humana, la que debe presidir la interpretación de sus normas y el proceso decisorio de los agentes públicos;

j) Exclusividad legal: la seguridad social debe ser regulada en sus aspectos medulares por normas de rango legal por razones de estabilidad jurídica, sin perjuicio de la celebración de convenios para la obtención de beneficios complementarios, por parte de sus beneficiarios (Novoa, 1977, pp. 83-118; Humeres, 2005, pp. 35-38; Bowen, 1974, pp. 116-119; Grzetich, 2005, pp. 25-56).

Un tema aparte lo constituye el principio de subsidiariedad, dadas las reformas estructurales introducidas recientemente a regímenes de la seguridad social en ciertos países. Para Novoa se trataba de una técnica de gestión operativa de la seguridad social, basada en un principio filosófico y político más amplio que involucraba a la comunidad -especialmente a los trabajadores, en la gestión 
administrativa de aquélla, sin implicar la primacía exclusiva del sector público o privado en dicha gestión, aunque reservando al Estado un papel rector en la materia (Novoa, 1977, pp. 472 y ss). Por su parte, Humeres (2005) sostiene que el principio aludido sólo es ". . . un elemento de administración o gestión del sistema, altamente positivo y que ha demostrado sus bondades en su aplicación en nuestro país" (p. 39), pero de aplicación restringida por sus efectos potencialmente regresivos y discriminatorios (Humeres, 2005, pp. 38 y ss).

Dados los efectos de la seguridad social y la cobertura perseguida, el financiamiento de la misma involucra a toda la población, pudiendo emplearse tanto mecanismos contributivos basados en el aporte de los beneficiados, empleadores o el Estado, como otros no contributivos basados en aportes fiscales. Sin ir más lejos, la Observación General considera entre las medidas efectivas que pueden adoptar los Estados, a título meramente enunciativo, para asegurar el derecho a la seguridad social, las siguientes: planes contributivos o planes basados en un seguro; planes no contributivos, como los planes universales o los planes de asistencia social destinados a determinados beneficiarios; planes privados y medidas de autoayuda u otras medidas, como los planes comunitarios o de asistencia mutua (Comité de Derechos Económicos, Sociales y Culturales, 2008, p. 2).

\section{El derecho fundamental a la seguridad social en la Constitución chilena}

La CPR asegura el derecho fundamental a la seguridad social en una perspectiva heterodoxa, desde el punto de vista del derecho constitucional comparado y de la historia constitucional chilena reciente (Obando, 2012, pp. 289-338).

En el texto original de la CPR - aprobado bajo el gobierno autoritario, este derecho fundamental se aseguraba en el contexto de un régimen democrático constitucional sujeto a Derecho, basado en un personalismo inmanente, en el principio de subsidiariedad, en la servicialidad del Estado y en la limitación de la soberanía nacional por los derechos esenciales que emanan de la naturaleza humana, como principios rectores de rango constitucional sobre las relaciones entre el Estado, la sociedad y el individuo. ${ }^{1}$ En consecuencia, el precepto constitucional referido al derecho en comento - el Art. $19 \mathrm{~N}^{\circ} 8 \mathrm{CPR}$, debía interpretarse congruentemente con los preceptos constitucionales que establecían las Bases de la Institucionalidad atingentes a dicho derecho - Arts. $1^{\circ}$ y $5^{\circ} \mathrm{CPR}$.

En una crítica extensiva a los diversos derechos asegurados constitucionalmente, Fernández ha sostenido recientemente que la preceptiva constitucional relativa éstos sugiere que lo asegurado es sólo la existencia jurídica del derecho, pero no garantiza su eficacia, ni su protección jurisdiccional, lo que explica su precariedad constitucional (Fernández, 2013, pp. 56, 61-71).

Esto no debe llamar a sorpresas, especialmente en materia de derechos sociales, económicos y culturales, pues la CPR siguió en ello una línea doctrinal claramente determinada desde los primeros documentos del gobierno autoritario. En esta constitución, según uno de sus redactores,

1 La parte dogmática de la CPR, constituida por los Capítulos I ("Bases de la institucionalidad"), II ("Nacionalidad y ciudadanía") y III ("De los derechos y deberes constitucionales"), se refieren a ello. 
“. . al Estado corresponde un papel subsidiario, lo que se traduce en un reconocimiento amplio de los derechos y libertades fundamentales, de modo que cada persona pueda decidir sobre su vida, y en una participación del sector privado en las prestaciones destinadas a hacer efectivos los derechos sociales..." (Bertelsen, 1987, p. 59).

Sin embargo, la incorporación del derecho internacional de la persona humana a la CPR, en virtud de la Ley $\mathrm{N}^{\circ} 18.825$, de 1989, obliga a analizar este derecho fundamental en una perspectiva integrada desde entonces, considerando ahora las normas, principios y valores jurídicos provenientes de ese derecho como parte integrante de la Carta Constitucional y, por ende, de la constitución material chilena. La incorporación de los derechos contemplados en aquél perfecciona -si no derechamente supera, el diseño constitucional originario aprobado en 1980 y permite, precisamente, cuestionar y problematizar el régimen jurídico atingente a dicho derecho fundamental, como se indica infra.

Por lo expuesto, el estatuto constitucional del derecho fundamental a la seguridad social será expuesto principiando por las normas referentes a las Bases de la Institucionalidad pertinentes, continuando con las normas jurídicas internacionales referentes al derecho en comento y finalizando con la regulación constitucional específica sobre este derecho, como señala infra.

\subsection{Bases de la Institucionalidad pertinentes al derecho fundamental a la seguridad social}

El Capítulo I CPR contempla las Bases de la Institucionalidad. Ellas consagran normas constitucionales que prefiguran el régimen establecido por el Constituyente, siendo pertinentes al derecho en análisis los Arts. $1^{\circ}$ y $5^{\circ} \mathrm{CPR}$.

El Art. $1^{\circ}$ consagra la libertad e igualdad originaria de las personas en términos de dignidad y derechos $\left(\right.$ Inc. $1^{\circ}$ ), el principio de subsidiariedad (Inc. $3^{\circ}$ ), el principio de servicialidad del Estado y su orientación finalista al Bien Común (Inc. $4^{\circ}$ ), y el deber estatal de protección a la población $\left(5^{\circ}\right.$ ). Este precepto prescribe, en lo pertinente:

Artículo $1^{\circ}$. Las personas nacen libres e iguales en dignidad y derechos. ... El Estado reconoce y ampara a los grupos intermedios a través de los cuales se organiza y estructura la sociedad y les garantiza la adecuada autonomía para cumplir sus propios fines específicos./ El Estado está al servicio de la persona humana y su finalidad es promover el bien común, para lo cual debe contribuir a crear las condiciones sociales que permitan a todos y cada uno de los integrantes de la comunidad nacional su mayor realización espiritual y material posible, con pleno respeto a los derechos y garantías que esta Constitución establece./ Es deber del Estado. . . dar protección a la población y a la familia,. . . y asegurar el derecho de las personas a participar con igualdad de oportunidades en la vida nacional (Constitución Política de la República de Chile, 2015.

El contenido teleológico de este precepto se ha proyectado en el ordenamiento jurídico, incidiendo en grado variable en una reducción del papel del Estado en el campo socio-económico. Tratándose de los derechos sociales, aquél se ha expresado en una “. . mayor libertad de opción de los beneficiarios de las prestaciones, la participación del sector privado en la ejecución de las mismas 
y una menor injerencia del Estado. .. " (Bertelsen, 1987, p. 61). La interpretación que el Tribunal Constitucional ha dado a este precepto es indicativa de esta relación entre el Estado y la sociedad, como se puede apreciar, en algunos de sus fallos.

Así, respecto de la libertad, el Tribunal Constitucional -citando a Linares Quintana, sostuvo que ". . . en caso de aparente conflicto entre la libertad y el interés del gobierno, aquélla debe primar siempre sobre este último, porque no se concibe que la acción estatal manifestada a través de los cauces constitucionales pueda resultar incompatible con la libertad, que es el fin último del Estado. . ."2 Igualmente, sobre el papel del Estado, señaló que

.. cuando la Carta Fundamental 'asegura' determinados derechos a las 'personas', sólo está reconociendo atributos propios de su naturaleza. ... no es la Constitución la que ha creado esos derechos sino que, simplemente, se ha limitado a reconocerlos, a regular su ejercicio y a garantizarlos a través de mecanismos jurídicos apropiados. . .

Asimismo, respecto de los grupos intermedios y el principio de subsidiariedad, señaló que

... la autonomía de los cuerpos asociativos. . . se configura, entre otros rasgos esenciales, por el hecho de regirse por sí mismos. ... No significa ello,. . . que puedan estos entes actuar de manera ilegal, . . amparándose en la referida autonomía, ya que de incurrir en excesos en su actuación quedan. . . sujetos a las responsabilidades consecuenciales. . .

Relacionando lo anterior con la servicialidad del Estado, estableció que “. . . la Carta Fundamental establece que el Estado está al servicio de la persona humana y su finalidad es promover el bien común, objetivo que impone al Estado el deber de amparar y garantizar la autonomía de los grupos intermedios. . ${ }^{5}$

Por otra parte, el Art. $5^{\circ}$ consagra la base institucional de la soberanía nacional (Inc. $1^{\circ}$ ) y su limitación fundada en el respeto a los derechos esenciales que emanan de la naturaleza humana (Inc. $2^{\circ}$ ). La reforma constitucional de la Ley $N^{\circ} 18.825$ agregó una parte final al Inc. $2^{\circ}$ de este artículo y estableció un deber de respeto y promoción de tales derechos por los órganos del Estado. En lo pertinente, este precepto prescribe lo siguiente:

Artículo $5^{\circ}$. La soberanía reside esencialmente en la Nación. Su ejercicio se realiza por el pueblo a través del plebiscito y de elecciones periódicas y, también, por las autoridades que esta Constitución establece. . .. El ejercicio de la soberanía reconoce como limitación el respeto a los derechos esenciales que emanan de la naturaleza humana. Es deber de los órganos del Estado respetar y promover tales derechos, garantizados por esta Constitución, así como por los tratados internacionales ratificados por Chile y que se encuentren vigentes.

\footnotetext{
Tribunal Constitucional Sentencia Rol Nº 325, de 2001.

3 Tribunal Constitucional, Sentencia Rol № 740, de 2008.

4 Tribunal Constitucional, Sentencia Rol № 184, de 1994. En el mismo sentido, Tribunal Constitucional, Sentencia Rol N ${ }^{\circ}$ 352, de 2002.

5 Tribunal Constitucional, Sentencia Rol N³.784, de 2009.
} 
El precepto transcrito se encuentra en congruencia con diversos preceptos de la parte dogmática de la CPR, especialmente con sus Arts. 19 a 23 CPR, referidos a los derechos y deberes constitucionales. Efectivamente, el Tribunal Constitucional sostuvo que

... el contenido del artículo 19 de la Carta Fundamental, conjuntamente con sus artículos $1^{\circ}, 4^{\circ}$ y $5^{\circ}$, inciso segundo, de la misma, configuran principios y valores básicos de fuerza obligatoria que impregnan toda la Constitución de una finalidad humanista que se irradia en la primacía que asignan sus disposiciones a la persona humana, a su dignidad y libertad natural, en el respeto, promoción y protección a los derechos esenciales que emanan de la naturaleza humana, que se imponen como limitación del ejercicio de la soberanía y como deber de los órganos del Estado. . . Debe desecharse toda interpretación de las normas constitucionales que resulte contradictoria con los aludidos principios y valores rectores de la Carta Suprema. . .

Así, la soberanía del Estado debe ceder teóricamente ante los derechos fundamentales, dada su relación con la libertad y dignidad humanas, pero sin que se garantice de antemano la vigencia real de algunos de estos derechos, particularmente de los derechos económicos, sociales y culturales.

La referencia que este precepto efectúa a los derechos fundamentales previstos en ciertos tratados internacionales, generó un debate en las últimas décadas sobre la fuerza normativa de estos tratados o de los derechos contemplados en ellos, según el caso. Este debate apuntó a esclarecer cómo debía tenerse por incorporado el derecho internacional de la persona humana al ordenamiento jurídico (Galdámez, 2014, p. 333).

Por una parte, se sostuvo que la reforma de la Ley $N^{\circ} 18.825$ reforzó la preocupación del Estado por los derechos fundamentales, dando un carácter dinámico a la CPR vigente, para exigir el respeto y promoción de todos los derechos humanos a aquél. No obstante, el precepto aludido no modificó la jerarquía normativa establecida por la CPR, dados los diversos controles de constitucionalidad impuestos a los tratados internacionales en esta última (Ríos, 1998, pp. 8-13). Al decir de Zúñiga (2008), la Constitución determinaba el lugar que ocupaban aquéllos entre las fuentes del derecho, porque contenía las reglas de competencia aplicables, más allá de toda inspiración garantista; por lo tanto, la jerarquía normativa de los tratados citados no fue modificada, pues sólo se les dotó de una eficacia especial derivada de su aplicación preferente (pp. 810 y ss).

Esta postura interpretativa fue acogida por el Tribunal Constitucional, aunque con ciertos matices. Así, aquél sostuvo inicialmente que

... el inciso segundo del artículo $5^{\circ}$, reformado en 1989 , no consagró que los tratados internacionales sobre derechos esenciales tuvieran una jerarquía igual o superior a la Ley Fundamental. No es posible sostener que un tratado que verse sobre derechos esenciales que emanan de la naturaleza humana enmiende la Constitución en lo que sea contraria a ella o tenga igual jerarquía. El sentido que debe darse a la frase agregada al artículo $5^{\circ}$ de la Constitución, es que el constituyente quiere dar énfasis a los derechos fundamentales, señalando que es deber para los órganos del Estado, respetarlos y promoverlos, no sólo los derechos asegurados en la Constitución, sino que también los contenidos en tratados internacionales ratificados

$\overline{6}$ Tribunal Constitucional, Sentencia Rol N 943, de 2008. 
por Chile y que se encuentren vigentes./ Sostener que los tratados internacionales sobre derechos humanos puedan modificar la Constitución, conduce a que pierdan eficacia las disposiciones que permiten el control previo de constitucionalidad de los tratados (artículo 82, № 1, de la Constitución) y el control a posteriori (artículo 80 de la Constitución)... ${ }^{7}$

Más tarde, el mismo tribunal precisó que los tratados referidos tienen una jerarquía supra-legal, pero sin dejar de estar sujetos a la CPR, como sigue: “. . la jerarquía normativa de los tratados, que es inferior a la de la Carta Fundamental, pero superior a cualquier otra norma jurídica y que las afirmaciones anteriores conservan. . pleno valor, incluso respecto de los tratados sobre derechos humanos esenciales."

Por otra parte, se sostuvo que la reforma citada incorporó los derechos fundamentales contemplados en los tratados internacionales directamente a la CPR, pasando éstos a tener la misma jerarquía que los derechos asegurados en ella. Al respecto, Cumplido sostuvo que ". . lo incorporado a la Constitución son los derechos sustantivos, no la parte adjetiva del tratado" (Cumplido, 2003, p. 370), por lo que la CPR comprendía los derechos asegurados en su Cap. III, en los tratados internacionales sobre derechos humanos ratificados por Chile y que se encontraren vigentes, $y$ ". . . todos los que sean necesarios para proteger la dignidad humana, teniendo en cuenta lo dispuesto en el Art. $1^{\circ}$, incisos 1 y 4, Art. $5^{\circ}$ inciso $2^{\circ}$ (SIC), ambos Bases de la Institucionalidad y el Art. 19 inciso $1 \mathrm{y} \mathrm{N}^{\circ}$ 26" (Cumplido, 2003, p. 370).

Esto llevó a proponer la categoría del bloque constitucional de los derechos fundamentales, inspirado en el derecho comparado. Nogueira (2008) sostuvo que la dignidad, libertad e igualdad de la persona humana constituían principios jurídicos que estructuraban, fundamentaban e irradiaban el ordenamiento jurídico, constituyendo la fuente de un catálogo abierto de derechos fundamentales, basado tanto en derechos explícitos como implícitos (pp. 267 y ss.). Para él, los derechos implícitos “. . . pueden deducirse de valores, principios, fines y razones históricas que alimentan el derecho positivo constitucional e internacional. El sistema de derechos humanos pleno tiene carencias normativas e implicitudes que es necesario extraer de los valores y principios, pudiendo faltar normas de reconocimiento" (Nogueira, 2008, p. 272). Este bloque limitaba a los órganos estatales y configuraba un parámetro de control de las normas infra-constitucionales, siendo definido por este autor como

... el conjunto de los derechos de la persona (atributos y garantías) asegurados por fuente constitucional o por fuente del derecho internacional de los derechos humanos (tanto el derecho convencional como el derecho consuetudinario y los principios de ius cogens), sin perjuicio de los derechos implícitos, expresamente incorporados ya sea por el propio texto constitucional por vía del artículo 29 literal c) de la CADH [Convención Americana de Derechos Humanos] (Nogueira, 2008, p. 280).

\footnotetext{
Tribunal Constitucional, Sentencia Rol N 346, de 2002. En el mismo sentido, Tribunal Constitucional, Sentencia Rol $N^{\circ}$ 46, de 1987; Tribunal Constitucional, Sentencia Rol N³09, de 2000; Tribunal Constitucional, Sentencia Rol № 1.288 , de 2008.

8 Tribunal Constitucional, Sentencia Rol N 346, de 2002. En el mismo sentido, Tribunal Constitucional, Sentencia Rol N ${ }^{\circ}$ 2.387-12, de 2013; Tribunal Constitucional, Sentencia Rol №2.388-12, de 2013.
} 
La Corte Suprema echó mano -indirectamente, a este concepto en diversos fallos en que hizo aplicación directa del derecho internacional consuetudinario. ${ }^{9}$ Además, señaló que el Art. $5^{\circ}$ Inc. $2^{\circ}$ CPR establece

... valores que son superiores a toda norma que puedan disponer las autoridades del Estado, incluido el propio Poder Constituyente derivado. . .. Otorgándole rango constitucional a los tratados que garantizan el respeto a los derechos humanos, concediéndoles una jerarquía mayor que a los demás tratados internacionales, en cuanto regulan los derechos esenciales que emanan de la naturaleza humana./ En definitiva, los derechos humanos asegurados en un tratado se incorporan al ordenamiento jurídico interno, formando parte de la Constitución material. . . ${ }^{10}$

Por su parte, el Tribunal Constitucional ha dictado algunos fallos recientes en los que deja entrever que los derechos fundamentales contenidos en ciertos tratados internacionales están incorporados en la CPR y operan como un límite material a la soberanía estatal, señalando al efecto que

. . la vulneración de los derechos a ser oído por un juez o tribunal competente, a un proceso público y a ser juzgado por un tribunal independiente e imparcial, constituye un conjunto de infracciones al artículo $8^{\circ}$ de la Convención Americana de Derechos Humanos. Este artículo tiene su correspondencia en el orden constitucional chileno a través del artículo $5^{\circ}$, inciso segundo, de la Constitución;. . . ${ }^{11}$

A la luz de estos fallos recientes y dado que Chile ha ratificado diversos tratados internacionales sobre derechos fundamentales que se encuentran vigentes, puede sostenerse que los derechos contemplados en ellos forman parte de su constitución material y constituyen parámetro del control de constitucionalidad de normas infra-constitucionales para el Tribunal Constitucional, resultando obligatorio -de esta forma, su respeto y promoción por todos los órganos del Estado.

\subsection{Normas jurídicas internacionales referentes al derecho fundamental a la seguridad social}

Diversos tratados internacionales vigentes contienen normas sobre el derecho fundamental a la seguridad social, aunque no todos ellos han sido ratificados por Chile. ${ }^{12}$

Si nos concentramos en el sistema general de derechos humanos de las Naciones Unidas, los siguientes tratados internacionales contienen preceptos jurídicos aplicables y que integran la constitución material chilena, a saber:

1. La Declaración Universal de los Derechos Humanos, de 1948, dispone en su Art. 22 que

... toda persona, como miembro de la sociedad, tiene derecho a la seguridad social, mediante el esfuerzo nacional y la cooperación internacional, habida cuenta

\footnotetext{
9 Corte Suprema, Sentencia Rol N 559-04, de 2006.

10 Corte Suprema, Sentencia Rol No 3.125-04, de 2007. En el mismo sentido, Corte de Apelaciones de Rancagua, Sentencia Rol N 103-2011, de 2011; Corte Suprema, Sentencia Rol № 10.608-2013, de 2013.

11 Tribunal Constitucional, Sentencia Rol N²492-13-INA, de 2014. En el mismo sentido, Tribunal Constitucional, Sentencia Rol N²273-12-INA, de 2013.

12 Para esta sección nos hemos basado en la enunciación efectuada por Nogueira (2008, pp. 449 y ss) y Arellano (2012, pp. 61 y ss), con algunas modificaciones pertinentes.
} 
de la organización y los recursos de cada Estado, la satisfacción de los derechos económicos, sociales y culturales, indispensables a su divinidad y al libre desarrollo de su personalidad.

El Art. $25 \$ 1$ de la Declaración preceptúa que

... toda persona tiene derecho a un nivel de vida adecuado que le asegure, así como a su familia, la salud y el bienestar, y en especial la alimentación, el vestido, la vivienda, la asistencia médica y los servicios sociales necesarios; tiene asimismo derecho a los seguros en caso de desempleo, enfermedad, invalidez, viudez, vejez u otros casos de pérdida de sus medios de subsistencia por circunstancias independientes de su voluntad.

2. El Pacto Internacional de Derechos Económicos, Sociales y Culturales, de 1966, en adelante el PIDESC, dispone en su Art. 9 que ". . . los Estados Partes en el presente Pacto reconocen el derecho de toda persona a la seguridad social, incluso al seguro social." El Art. $10^{\circ} \$ 2$ del pacto prescribe que “. . se debe conceder especial protección a las madres durante un período de tiempo razonable antes y después del parto. Durante dicho período, a las madres que trabajen se les debe conceder licencia con remuneración o con prestaciones adecuadas de seguridad social."

3. La Convención Internacional sobre la Eliminación de todas las Formas de Discriminación Racial, de 1965, establece, en su Art. 5 e) iv), que los Estados partes se comprometen ". . . a garantizar el derecho de toda persona a la igualdad ante la ley, sin distinción de raza, color y origen nacional o étnico, particularmente en el goce de los derechos siguientes:/ e) Los derechos económicos, sociales y culturales, en particular,/ iv) El derecho a. . la seguridad social y los servicios sociales."

4. La Convención sobre la Eliminación de todas las Formas de Discriminación contra la Mujer, de 1979, contempla, en su Art. 11. 1., la obligación de los Estados partes de

... adoptar todas las medidas apropiadas para eliminar la discriminación contra la mujer en la esfera del empleo a fin de asegurar a la mujer, en condiciones de igualdad con los hombres, los mismos derechos, en particular: / e) El derecho a la seguridad social, en particular en casos de jubilación, desempleo, enfermedad, invalidez, vejez u otra incapacidad para trabajar, así como el derecho a vacaciones pagadas. . .

El Art. 14. 2. c), por su parte, contempla una obligación estatal similar respecto de la mujer de las zonas rurales, debiendo asegurarle especialmente el derecho a ". . . beneficiarse directamente de los programas de seguridad social."

5. La Convención sobre Derechos del Niño, de 1989, preceptúa en su Art. 26. 1. que los Estados partes “. . . reconocerán a todos los niños el derecho a beneficiarse de la seguridad social, incluso del seguro social, y adoptarán las medidas necesarias para lograr la plena realización de este derecho de conformidad con su legislación nacional." El numeral 2. de este artículo se refiere a la forma de otorgar las prestaciones y señala que 
“. . las prestaciones deberían concederse, cuando corresponda, teniendo en cuenta los recursos y la situación del niño y de las personas que sean responsables del mantenimiento del niño, así como cualquier otra consideración pertinente a una solicitud de prestaciones hechas por el niño o en su nombre."

Si pasamos revista al sistema interamericano de derechos humanos, los instrumentos jurídicos pertinentes se reducen bastante, ya que Chile no ha ratificado el Protocolo Adicional a la Convención Americana sobre Derechos Humanos en materia de Derechos Económicos. Sociales y Culturales ("Protocolo de San Salvador"), de 1988. ${ }^{13}$ Así, podemos mencionar los tratados internacionales siguientes:

1. La Carta de la Organización de Estados Americanos, de 1948, dispone en su Art. 45 que los Estados miembros convienen en aplicar sus máximos esfuerzos al ". . . desarrollo de una política eficiente de seguridad social, e. .."

2. La Declaración Americana de los Derechos y Deberes del Hombre, de 1948, establece en su Art. XVI que “. . . toda persona tiene derecho a la seguridad social que le proteja contra las consecuencias de la desocupación, de la vejez y de la incapacidad que, proveniente de cualquier otra causa ajena a su voluntad, la imposibilite física o mentalmente para obtener los medios de subsistencia."

En la normativa sectorial sobre la seguridad social, deben realzarse los instrumentos jurídicos internacionales vigentes aprobados por la OIT y ratificados por Chile, los que integran también su constitución material en cuanto establecen derechos fundamentales (Arellano, 2012, pp. 127-129).

Sobre el particular, la OIT considera entre sus fines y objetivos el acceso a la seguridad social, especialmente tras la aprobación de la Declaración de Filadelfia, de 1944. Esta última, incluida como un anexo en la Constitución de la OIT, de 1919, titulado Declaración Relativa a los Fines y Objetivos de la OIT, contempla una obligación solemne sobre la seguridad social que pesa sobre los Estados partes, cual es fomentar programas que permitan, entre otros,

...f) extender las medidas de seguridad social para garantizar ingresos básicos a quienes los necesiten y prestar asistencia médica completa; g) proteger adecuadamente la vida y la salud de los trabajadores en todas las ocupaciones; h) proteger a la infancia y a la maternidad; (i) suministrar alimentos, vivienda y medios de recreo y cultura adecuados...

Según Arellano (2012, pp. 95-97), tanto la Constitución, como la Declaración antedicha, constituyen instrumentos constitucionales de la OIT y, conforme a la Declaración de la OIT Relativa a los Principios y Derechos Fundamentales en el Trabajo, de 1998, en adelante la Declaración, los principios contenidos en ellos se entienden aceptados por los Estados partes, por el solo hecho de

13 Cfr. Art. 9 del Protocolo Adicional a la Convención Americana sobre Derechos Humanos en materia de Derechos Económicos, Sociales y Culturales, de 1988. 
incorporarse a la OIT, comprometiéndose a lograr sus objetivos generales. Este autor sostiene que la Resolución se ha entendido como una interpretación de la Declaración, por lo que sus conclusiones constituyen también normas constitucionales de esta organización y son vinculantes para todos los Estados partes, entre las cuales debe destacarse la que concibe a la seguridad social como un derecho fundamental (Arellano, 2012, pp. 95-97).

A esto debe agregarse la reciente Recomendación N²02, de la OIT, Sobre los Pisos de Protección Social, en adelante la Recomendación y que, como indica su Preámbulo, reafirma que “. . . el derecho a la seguridad social es un derecho humano" y complementa las normas existentes sobre la seguridad social y orienta a los Estados partes para establecer pisos de protección social “. . . adaptados a las circunstancias y niveles de desarrollo de cada país, como parte de sistemas integrales de seguridad social." Ella ha incidido, en grado variable, en las políticas de protección y desarrollo social llevadas a cabo por los dos últimos gobiernos chilenos.

Adicionalmente, existen los convenios de la OIT. ${ }^{14}$ En el ámbito de la seguridad social, ellos suman alrededor de una docena y han tenido un impacto en la legislación nacional al establecer niveles normativos mínimos, entre los cuales pueden mencionarse los siguientes: $N^{\circ} 12$, de 1925 , sobre la indemnización por accidentes del trabajo (agricultura); $\mathrm{N}^{\circ} 19$, de 1925, sobre igualdad de trato (accidentes del trabajo); Nos 24 y 25, de 1927, sobre seguro de enfermedad en la industria y agricultura, respectivamente; $\mathrm{N}^{\circ} \mathrm{s} 35$ y 36, de 1933, sobre seguro de vejez en la industria y la agricultura, respectivamente; $N^{\circ}$ s 37 y 38, de 1933, sobre seguro de invalidez en la industria y la agricultura, respectivamente; $\mathrm{N}^{\circ} 103$, de 1952, sobre protección a la maternidad; № 121, de 1964, sobre prestaciones en caso de accidentes del trabajo y enfermedades profesionales; $N^{\circ} 161$, de 1999 , sobre servicios de salud en el trabajo; $N^{\circ} 187$, de 2006, sobre marco promocional para la seguridad y la salud en el trabajo. Con todo, el principal instrumento internacional sectorial en la materia, que es el Convenio $\mathrm{N}^{\circ} 102$, de 1952, sobre la seguridad social (norma mínima), no ha sido ratificado por Chile - al igual que otros convenios, por dificultades para aplicar sus normas sobre prestaciones sociales a las pensiones, vejez y sobrevivencia que contempla el "Nuevo Régimen de Pensiones", explicado infra (Gumucio, 2009, p. 170).

\subsection{Regulación constitucional específica sobre el derecho fundamental a la seguridad social}

La CPR asegura el derecho fundamental a la seguridad social en su Art. $19 \mathrm{~N}^{\circ} 18$, cuyo tenor es el siguiente:

Artículo 19. La Constitución asegura a todas las personas:/ 18². El derecho a la seguridad social./ Las leyes que regulen el ejercicio de este derecho serán de quórum calificado./ La acción del Estado estará dirigida a garantizar el acceso de todos los habitantes al goce de prestaciones básicas uniformes, sea que se otorguen a través

$\overline{14}$ Arellano (2012) dice que estos representan “... una técnica de extensión de la cobertura a un nivel mínimo y tratan los aspectos prácticos de la aplicación del derecho a la seguridad social a nivel local” (p. 76). 
de instituciones públicas o privadas. La ley podrá establecer cotizaciones obligatorias./ El Estado supervigilará el adecuado ejercicio del derecho a la seguridad social.

Este es el tenor literal del precepto constitucional aprobado originariamente en 1980.

Desde luego, llama la atención la parquedad e imprecisión del Constituyente, como acontece con la mayoría de los derechos económicos, sociales y culturales contemplados en la CPR. Al decir de Fernández (2013), estos derechos adolecen de una debilidad preceptual profunda en la Carta Constitucional, lo que lleva a considerarlos como ejemplos de "derechos precarios", uno de los cuales es el derecho en comento (pp. 51 y ss). La inserción de este precepto dentro de la discusión habida sobre el Orden Público Económico, que trata sobre el régimen económico-social de inspiración neoliberal de la CPR, explica precisamente los silencios, omisiones e imprecisiones de aquél (Obando, 2012, pp. 289-338).

Ahora bien, una lectura atenta del precepto constitucional revela que éste no señala en qué consiste el derecho, esto es, no indica -ni siquiera a título enunciativo, cuáles son los riesgos y contingencias sociales cubiertos por este derecho, a diferencia de la constitución chilena precedente, por lo que el texto constitucional es absolutamente silente sobre el grado de universalidad respectivo.

Esto implica que toda decisión política fundamental en la materia queda entregada al legislador y debe ser éste el que determine los riesgos y contingencias sociales cubiertas por la legislación, como asimismo los principios que inspiren el sistema de seguridad social, dentro del marco dogmático de la CPR. En otras palabras, esta última no establece cuál es el núcleo del derecho referido, por lo que su determinación es remitida al legislador, el que ha sido auxiliado por la doctrina recientemente, como señalado infra (Fernández, 2013, pp. 85 y ss).

Respecto de este punto, el legislador encuentra actualmente claras prescripciones y orientaciones provenientes del derecho internacional de la persona humana, dado el cambio jurisprudencial reciente, por lo que aquél ya no cuenta con una tabula rasa en la materia, a diferencia de lo acontecido con la reforma estructural a la seguridad social realizada por el gobierno autoritario en 1980.

Es así que la Observación General establece que el sistema de seguridad social debe comprender nueve ramas principales, las que permiten inferir los riesgos y contingencias sociales pertinentes, a saber: acceso adecuado a los servicios de salud (atención de salud), lo que es materia de un derecho constitucional diferente en la constitución chilena; otorgamiento de prestaciones en efectivo durante los periodos de pérdidas de ingreso a las personas imposibilitadas de trabajar por razones de salud (enfermedad); concesión de prestaciones a las personas de edad, a partir de una edad determinada prescrita por la ley (vejez); tratar de ofrecer prestaciones para sufragar la pérdida o falta de ingresos debida a la incapacidad de obtener o mantener un empleo adecuado (desempleo); sufragar los gastos y la pérdida de ingresos resultante de la lesión o condición de morbilidad, así como la pérdida de apoyo que sufran el cónyuge supérstite o las personas a cargo como consecuencia del fallecimiento del sostén de la familia (accidentes laborales); otorgar prestaciones familiares, incluidas las prestaciones en efectivo y los servicios sociales (prestaciones sociales); otorgar licencias con remuneración o con prestaciones adecuadas (maternidad); prestar apoyo suficiente a los ingresos de las personas con discapacidad que, por su condición o factores relacionados, hubieren perdido tem- 
poralmente o visto reducidos sus ingresos (discapacidad); conceder prestaciones de supervivencia y de orfandad a la muerte del sostén de familia afiliado a la seguridad social o con derecho a pensión (sobrevivientes y huérfanos).

Respecto de los principios inspiradores, la Observación General reconoce los siguientes principios como rectores de un sistema de seguridad social: solidaridad, por su carácter redistributivo $(\$ 3$ y $\$ 50)$; integridad o suficiencia $(\$ 9$ y $\$ 22)$; igualdad y no discriminación, especialmente en términos de género $(\mathbb{S} 9$ y $\$ 29)$; universalidad objetiva $(\mathbb{S} 12)$; protector $(\mathbb{S} 22)$; universalidad subjetiva (\$23); participación (\$25); internacionalidad (\$ 6); unidad (\$48 y \59 a); exclusividad legal (\$48). A lo anterior deben sumarse otros principios provenientes del derecho internacional de la persona humana, como disponibilidad y sustentabilidad (\$11); accesibilidad ( $\$ 23$ a $\$ 27$ ), entre otros.

Cabe agregar que el Tribunal Constitucional integró el precepto constitucional hace casi cinco años atrás, limitando la libertad del legislador para el futuro y señaló que son de la esencia del derecho en comento, dotando a éste de una identidad específica, los principios de universalidad, integridad o suficiencia, unidad y solidaridad, ${ }^{15}$ los que el Estado debe observar en el ejercicio de los cometidos estatales en la materia y que la Observación General traduce en las obligaciones específicas de respetar, proteger y cumplir (\$ 44 a $\ 51$ ). Además, relacionando este derecho con la dignidad de la persona humana, dicho tribunal declaró que este derecho

. . . tiene su razón de ser en que los administrados están sujetos a contingencias sociales. La necesidad de proteger de estas contingencias al ser humano y a los que de él dependen emana de su derecho a la existencia; de la obligación de conservar su vida y hacerlo en un nivel digno y acorde con su condición de tal. ${ }^{16}$

La CPR prescribe que el ejercicio del derecho deberá ser regulado por una ley de quórum calificado, con lo cual el legislador debe precisar además la forma de impetrar las prestaciones por los beneficiarios y las garantías existentes al respecto, en el marco constitucional descrito supra. Dada la mención que se hace a la ley de quórum calificado, debemos recordar que ésta es aquella que requiere para su aprobación, derogación o modificación del voto conforme de la mayoría absoluta de los diputados y senadores en ejercicio, según el Art. 66 Inc. $3^{\circ} \mathrm{CPR}$. La iniciativa de ley respectiva constituye una atribución exclusiva del Presidente de la República, quien goza de iniciativa exclusiva de ley para ". . establecer o modificar las normas sobre seguridad social o que incidan en ella, tanto del sector público como del sector privado", acorde al Art. 65 Inc. $4^{\circ} \mathrm{N}^{\circ} 6^{\circ} \mathrm{CPR}$.

En los términos expuestos, el precepto constitucional acoge el principio de la exclusividad legal, lo que brinda estabilidad jurídica a las instituciones legales respectivas; sin embargo, el alto quórum parlamentario exigido para la aprobación, modificación o derogación de este tipo de preceptos legales dificulta, obviamente, su reforma por vía legislativa, como asimismo el establecimiento de instituciones innovadoras que estén más acordes a los principios rectores, enunciados supra.

\footnotetext{
15 Tribunal Constitucional, Sentencia Rol N 1.287-08-INA, de 2009; Tribunal Constitucional, Sentencia Rol N 1.710-10INC, de 2010.

16 Tribunal Constitucional, Sentencia Rol N 1710, de 2010.
} 
Rigidizando aún más el sistema de seguridad social, la CPR dispone en su Art. 105 Inc. $1^{\circ}$ que el régimen de seguridad social aplicable a los integrantes de las Fuerzas Armadas y Carabineros de Chile constituye materia de ley orgánica constitucional, la que requiere de un quórum parlamentario mucho más alto para su aprobación, modificación o derogación, cual es 4/7 de los diputados y senadores en ejercicio. Estas leyes fueron dictadas en las postrimerías del gobierno autoritario y son las leyes $\mathrm{N}^{\circ} \mathrm{s}$ 18.498 y 18.961, incorporándose otras fuerzas de orden y seguridad al régimen de Carabineros de Chile, como la Policía de Investigaciones y Gendarmería de Chile, en virtud de leyes diversas.

Resguardando todo lo anterior, tanto el Art. 19 N 18 como el Art. 105 Inc. 1, ambos CPR, se ubican en aquellos capítulos de la Carta Constitucional cuya reforma requiere de un quórum parlamentario agravado y superior al que se requiere por regla general para reformar la constitución. En efecto, el Art. 127 Inc. $2^{\circ} \mathrm{CPR}$ prescribe que la modificación de ambos preceptos requiere de la concurrencia de $2 / 3$ de los diputados y senadores en ejercicio. En resumen, la rigidez constitucional refuerza la rigidez del régimen legal pertinente.

La CPR asigna dos deberes ineludibles y exclusivos al Estado, cada uno de los cuales es expresión de los principios de subsidiariedad y servicialidad del Estado previstos en el Art. $1^{\circ} \mathrm{CPR}$, a saber: a) Garantizar el acceso de todos los habitantes al goce de prestaciones básicas uniformes, sea que se otorguen por instituciones públicas o privadas; b) Supervigilar el adecuado ejercicio del derecho.

El primer deber, transcrito supra, se traduce en que la CPR asegura ampliamente a las personas, sin distinción de nacionalidad, tomar parte en las prestaciones de la seguridad social, en calidad de beneficiario, previo cumplimiento de los requisitos legales, de lo que se deduce la adopción del principio de universalidad subjetiva. El Estado, entonces, debe desarrollar su acción gubernamental para extender el acceso de todas las personas a los distintos programas de seguridad social autorizados por la ley, dando a éstos la cobertura deseada en términos de riesgos y contingencias sociales, por lo que deberá aprobar una política nacional de seguridad social, crear programas, financiarlos total o parcialmente, aumentar la cobertura de los existentes, enfrentar las barreras de acceso que afectan a ciertos grupos, entre otros, para lo cual deberá dictar la legislación pertinente, ejecutar las leyes existentes y resolver las controversias que surjan al respecto.

Este deber estatal recoge en parte las obligaciones específicas de respetar y cumplir, que pesan sobre los Estados partes, previstas en la Observación General ( $\$ 44$ y $\$ 47$ a $\$ 51$ ). En todo caso, el Estado encuentra serias limitaciones en adoptar deliberadamente medidas regresivas en materia de seguridad social, atendido el tenor del $\$ 42$ de la Observación General, que coloca sobre los Estados partes la carga de la prueba de que tales medidas obedecen a un estudio razonado y detallado de los diversos cursos de acción y que están justificadas acorde a los derechos previstos en el PIDESC y considerando el ". . p pleno aprovechamiento del máximo de los recursos de que dispone el Estado parte", como indica la Observación General precitada.

Sin perjuicio de lo anterior, existe la garantía jurídica de la esencia del derecho fundamental a la seguridad social, asegurado en el Art. 19 N²6 CPR y, tratándose de las prestaciones sociales propiamente tales, la acción constitucional de protección de derechos constitucionales que se puede 
interponer por privación, perturbación o amenaza en el legítimo ejercicio del derecho de igualdad ante la ley y de propiedad, conforme al Art. 20 CPR, como se señala infra.

La CPR admite que las prestaciones de seguridad social puedan otorgarse por instituciones públicas -controladas total o parcialmente al Estado, o privadas -controladas por personas privadas o la comunidad organizada, lo que abre el camino para que personas jurídicas de derecho privado puedan otorgar dichas prestaciones. Esto indica que la CPR no reservó -forzosamente, la actividad prestacional de la seguridad social a instituciones públicas de origen estatal; por lo demás, difícilmente podía haberlo hecho según los principios de subsidiariedad y servicialidad del Estado, referidos supra. ${ }^{17}$

El precepto comentado obliga a hacer una distinción en este derecho fundamental, la que tiene relevancia para efectos de su exigibilidad en estrados judiciales, como indicado infra. Como dice Arellano, el sujeto responsable de garantizar el derecho de acceso a las prestaciones de seguridad social es el Estado, pero quien debe otorgar materialmente dichas prestaciones puede no ser necesariamente este último, como sucede frecuentemente, pues los sujetos responsables del pago de las múltiples prestaciones de la seguridad social suelen ser usualmente instituciones privadas, teniendo lugar -en ocasiones, una verdadera dicotomía entre el derecho fundamental asegurado constitucionalmente por el Estado y la gestión propiamente tal de los riesgos y contingencias sociales, usualmente en manos de personas privadas (Arellano, 2012, pp. 154 y ss).

Cabe agregar que la CPR cualifica este primer deber al indicar que el acceso se refiere al goce de prestaciones uniformes, por lo que la determinación de estas últimas, incluidos sus requisitos de acceso y sus bases de cálculo, debe basarse en los mismos elementos para quienes se encuentran en idéntica condición previsional o social, eliminado toda diferenciación no razonable, sin perjuicio de la protección adicional que puedan procurarse las personas de acuerdo a su capacidad de ahorro individual. Esto sugiere la adopción del principio de la igualdad en sentido no sustancial, especialmente tras fallos recientes del Tribunal Constitucional, mencionados supra.

Aún más, el acceso se debe garantizar a todas las personas sobre bases igualitarias y no discriminatorias, pues el Art. $19 \mathrm{~N}^{\circ} 2$ Inc. $2^{\circ} \mathrm{CPR}$ prohíbe a la ley o a autoridad alguna efectuar toda diferenciación arbitraria, esto es, carente de razonabilidad o motivada en un capricho. Por ello, el Tribunal Constitucional ha resuelto que

... no repugna a las disposiciones constitucionales que en el goce de prestaciones de seguridad social, el Estado pueda amparar especialmente a quienes sufren un mayor grado de carencia, siempre que ello no vulnere, como se explicó, la igualdad ante la ley, introduciendo diferencias de trato que no sean objetivas y razonables, que no estén soportadas en un fin de carácter general y que, en fin, no sean tolerables para quien sufre menoscabo de su derecho. ${ }^{18}$

Con todo, existen límites respecto de las obligaciones del Estado, pues

\footnotetext{
17 Respecto de este derecho, Bertelsen (1987) sostuvo que el Estado tenía un papel contralor, protector del ejercicio del derecho y garante de la ejecución de ciertas acciones, ". . . pero no asume -como ocurría anteriormente, una responsabilidad exclusiva en el logro de las finalidades que la Constitución protege" (p. 61).

18 Tribunal Constitucional, Sentencia Rol N 790, de 2007.
} 
... hacer extensivo el reajuste de pensiones que el legislador acuerde para aquellos regímenes que son de exclusiva responsabilidad del Estado. . ., a otros en que no tiene ninguna participación en su administración, financiamiento y pago, salvo las pensiones mínimas garantizadas. .., es imponerle una obligación a la que no está obligado ni legal ni constitucionalmente no pudiendo consecuencialmente servir de fundamento a una pretendida desigualdad. ${ }^{19}$

El precepto constitucional indica, asimismo, que las prestaciones uniformes cuyo acceso se asegura tendrán un carácter básico, lo que significa que ellas deben proveer un mínimo necesario para enfrentar el riesgo y contingencia social correspondiente al beneficiario, de lo que se deduce la adopción - aparentemente, parcial del principio de integridad o suficiencia por el texto constitucional. En todo caso, la apreciación del carácter básico de las prestaciones queda entregada a los órganos estatales competentes, aunque el precepto en comento no impide que los propios beneficiarios puedan procurarse prestaciones de un nivel superior a través de los distintos mecanismos pertinentes, como quedó establecido en la historia fidedigna del establecimiento de la norma.

Para el financiamiento de la seguridad social, el precepto constitucional autoriza expresamente a la ley para imponer el pago de cotizaciones obligatorias, sin identificar el sujeto responsable del pago de las mismas. Este puede ser el propio beneficiario y/o- el empleador, dependiendo del riesgo y contingencia social de que se trate. Dada la redacción del precepto, su tenor sugiere también una autorización implícita para crear eventualmente sistemas de seguridad social basados en el aporte fiscal y destinados a otorgar prestaciones a quienes no pueden sufragar el coste de las mismas o el de las cotizaciones recién mencionadas, ya sea por su bajo ingreso económico o su nula o baja capacidad de ahorro. La CPR, por lo tanto, permite la adopción de planes o programas de carácter contributivo como no contributivo; en cualquier caso, los fallos recientes del Tribunal Constitucional, mencionados supra, deben conducir al Estado a coordinar debidamente las medidas basadas en la subsidiariedad y en la solidaridad, a la luz de lo dispuesto en el Art. $1^{\circ} \mathrm{CPR}$.

La Resolución, en este punto, admite opciones diversas de financiamiento de la seguridad social, incluyendo la financiación tripartita, acorde al carácter solidario de aquélla, como se desprende de sus Conclusiones 2. y 16. Y agrega en su Conclusión 4. que

... no existe un modelo idóneo único de seguridad social. ... Cada sociedad debe elegir cuál es la mejor forma de garantizar la seguridad de ingresos y el acceso a la asistencia médica. Esta elección reflejará sus valores sociales y culturales, su historia, sus instituciones y su nivel de desarrollo económico. ...La función prioritaria del Estado es facilitar, promover y extender la cobertura de la seguridad social. . .. los regímenes deberían administrarse de forma sana y transparente, con costos administrativos tan bajos como sea factible y una fuerte participación de los interlocutores sociales. . .

Sobre el particular, la Observación General indica que en los planes de seguridad social basados en la contribución privada ". . . debe haber una relación razonable entre los ingresos, las cotizaciones abonadas y la cuantía de la prestación pertinente" (\$22), cuestión que es de la mayor

19 Tribunal Constitucional, Sentencia Rol N²19, de 1995. 
importancia para los sistemas de pensión de vejez basados en la capitalización individual, como el existente en Chile y que ha generado no pocas críticas de organismos internacionales, las que han llevado a introducirle modificaciones en el pasado reciente, como señalado infra (Oficina del Alto Comisionado de las Naciones Unidas para los Derechos Humanos, 2004, p. 64).

Dada la importancia de las cotizaciones obligatorias, el Tribunal Constitucional ha relacionado estas últimas con el derecho de propiedad de los cotizantes, a propósito del "Nuevo Régimen de Pensiones" basado en la capitalización individual de aquéllos. El Tribunal ha dicho que

... el acceder a la seguridad social conlleva restricciones y disciplinas que se traducen en serias limitaciones a la propiedad y sus atributos. Así, la obligación de ahorrar un porcentaje de las remuneraciones, la prohibición de disponer de dichos ahorros durante un largo lapso, la privación de su administración y las restricciones al destino que pueden darle las Administradoras, son algunas de sus expresiones, que derivan de la función social de dominio, que dispone el número $24^{\circ}$ del artículo 19 de la Constitución. La voluntad del constituyente ha sido establecer exigencias en torno al derecho de propiedad para la debida consecución de la seguridad social. . . ${ }^{20}$

No está demás decir que parece curioso que se afirme la existencia de un derecho de propiedad de los cotizantes sobre cotizaciones previsionales que están en manos de personas privadas, que las invierten y cobran por ello comisiones a los cotizantes, sin que estos últimos puedan hacer uso, goce o disposición de dichos bienes, sino hasta el término de su vida laboral.

En este mismo orden de ideas, el Tribunal Constitucional se ha pronunciado sobre la naturaleza de los derechos públicos subjetivos de la seguridad social, a propósito del mismo régimen y, en un fallo no del todo claro, ha establecido que

... importan verdaderas facultades de los administrados frente a la administración, quienes por su naturaleza de personas son acreedoras al otorgamiento de las prestaciones necesarias para cumplir y satisfacer sus necesidades y lograr su bienestar. Ello ha llevado incluso a la doctrina a consignar que los derechos públicos subjetivos de la seguridad social -entre los que se encuentra ciertamente el derecho y deber de cotizar- se caracterizan por ser: a) patrimoniales, en tanto forman parte del patrimonio de las personas, destinadas a asistirlas para que puedan llevar una vida digna, cuando se verifique algún estado de necesidad; b) personalísimos, de modo que son inalienables e irrenunciables; c) imprescriptibles, en cuanto las personas siempre podrán requerir al Estado o a los particulares que, en virtud del principio de subsidiariedad, administran parte del sistema, los beneficios para aplacar el estado de necesidad que los afecte, y d) establecidos en aras del interés general de la sociedad. ${ }^{21}$

Y decimos que el fallo no es del todo claro porque parece confundir el derecho propiamente tal con el otorgamiento de las prestaciones respectivas, en circunstancias que un régimen jurídico de pensiones de vejez, invalidez y sobrevivencia basado en una gestión presuntamente subsidiaria, a manos de privados, como el chileno, implica una relación triangular que involucra al Estado garante, al gestor/prestador usualmente privado y al cotizante beneficiario, el que carece de libertad de con-

20 Tribunal Constitucional, Sentencia Rol N 5.627, de 2007.

21 Tribunal Constitucional, Sentencia Rol N576, de 2006. 
tratar respecto de ciertos riesgos y contingencias sociales por disposición de la ley (Arellano, 2012, pp. 156, 300 y ss).

El segundo deber estatal, transcrito supra, asigna al Estado un papel contralor respecto del ejercicio adecuado de este derecho. El Estado, por lo tanto, deberá velar por el funcionamiento legal y efectivo de las instituciones encargadas de atender los requerimientos de los beneficiarios y otorgar las prestaciones respectivas, para lo cual deberá poner en acción su actividad judicial y administrativa contralora. Al igual que el primer deber estatal, éste se encuentra en consonancia con los principios constitucionales de subsidiariedad y servicialidad del Estado; además, recoge la obligación específica de proteger, que pesa sobre los Estados partes, prevista en la Observación General ( $\$ 45$ y \46).

Este deber se ejerce especialmente por medio de la Administración Fiscalizadora del Estado. En esta materia debe destacarse que la fiscalización de las pensiones de vejez, invalidez y sobrevivencia, tanto del nuevo régimen de pensiones basado en la capitalización individual e incluyendo el sistema de pensiones solidarias creado en 2008, como del antiguo régimen previsional basado en el reparto, corresponde a la Superintendencia de Pensiones, dependiente del Ministerio del Trabajo y Previsión Social, con exclusión del régimen previsional de las Fuerzas Armadas y de Orden y Seguridad Pública, el que es fiscalizado en cuanto a sus objetivos por el Ministerio de la Defensa Nacional y por el Ministerio del Interior y de Seguridad Pública, según el caso. En cuanto al seguro de accidentes del trabajo y enfermedades previsionales; créditos sociales otorgados por Cajas de Compensación de Asignación Familiar; prestaciones de carácter familiar y subsidios maternales, subsidios por discapacidad, bodas de oro y al empleo; licencias médicas y permisos postnatales, entre otros, el Estado ejerce su fiscalización a través de la Superintendencia de Seguridad Social, dependiente del Ministerio del Trabajo y Previsión Social.

Como una garantía jurídica del derecho, la CPR asegura el contenido esencial de este derecho, frente a la intervención legislativa, en un precepto inspirado también en el derecho comparado. El Art. $19 \mathrm{~N}^{\circ} 26$ prescribe:

Artículo 19. La Constitución asegura a todas las personas:/ $26^{\circ}$. La seguridad de que los preceptos legales que por mandato de la Constitución regulen o complementen las garantías que ésta establece o que las limiten en los casos en que ella lo autoriza, no podrán afectar los derechos en su esencia, ni imponer condiciones, tributos o requisitos que impidan su libre ejercicio.

Basado en el derecho internacional de la persona humana y ante la parquedad u omisiones del Constituyente, Nogueira (2008) ha establecido recientemente que el contenido esencial del derecho a la seguridad social se traduce en

... el derecho de acceso a las prestaciones de seguridad social configuradas legislativamente, sin discriminación alguna; el derecho a no ser privado arbitrariamente de ellas; y un derecho a la no reversibilidad de las prestaciones ya incorporadas al patrimonio de la persona; como asimismo, un derecho a la irreversibilidad de las prestaciones que asegura y garantiza el ordenamiento jurídico, sin que ellas puedan ser disminuidas sin que exista una justificación razonable, en consideración del conjunto de los derechos y haciendo uso del máximo de los recursos disponibles (p. 457). 
Este contenido esencial puede ser cautelado -con eficacia variable, por medio de la acción de inconstitucionalidad o la excepción de inaplicabilidad de todo precepto legal contrario a la CPR y de los cuales conoce el Tribunal Constitucional según el Art. 93 Ns 6 y 7 CPR.

Con todo, el derecho a la seguridad social no se encuentra cautelado por la acción constitucional de protección de derechos constitucionales, prevista en el Art. 20 CPR, ${ }^{22}$ precarizando normativamente este derecho, fenómeno que Fernández (2013) representa mediante la expresión ". . desgaranticidad preceptual" (p. 80). Efectivamente, esta acción constitucional, similar al habeas corpus, resulta improcedente respecto de tal derecho, pues este último no se encuentra entre aquellos susceptibles de ser amparados por su intermedio, en caso de algún acto ilegal o arbitrario que amenace, prive o perturbe el legítimo ejercicio de aquél.

No obstante, los Tribunales Superiores de Justicia (Excma. Corte Suprema e Iltmas. Cortes de Apelaciones) han fallado numerosas acciones interpuestas por actos ilegales o arbitrarios que han causado privación, perturbación o amenaza de otros derechos fundamentales, pero relacionados con aspectos del derecho en comento o de la actividad prestacional respectiva, como la igualdad ante la ley (Art. $19 \mathrm{~N}^{\circ} 2 \mathrm{CPR}$ ) y el derecho de propiedad sobre toda clase de bienes, corporales o incorporales (Art. $\left.19 \mathrm{~N}^{\circ} 24 \mathrm{CPR}\right)$.

De esta forma, al decir de Fernández (2013), el contenido del derecho fundamental a la seguridad social es subsumido ". . . en otros derechos sí ubicados bajo la protección" (p. 69). Precisamente, esta circunstancia permite la interposición de dicha acción constitucional no sólo en contra del Estado por su actividad normativa y material administrativa, sino también, la mayor parte del tiempo, en contra de las personas privadas que gestionan los riesgos y contingencias sociales y, por lo tanto, otorgan las prestaciones sociales en materia previsional y de salud, lo que - según Arellano (2012), ha contribuido afirmar la eficacia horizontal de los derechos fundamentales en la doctrina $y$ jurisprudencia (p. 154 y ss).

\section{El régimen legal relativo al derecho fundamental de la seguridad social: déficits normativos}

Una revisión del marco legal y la gestión de algunos riesgos y contingencias sociales, con exclusión de la salud y la asistencia social, sugiere la existencia de déficits normativos a la luz del derecho internacional de la persona humana que integra la constitución material chilena y promueve dudas sobre la observancia real del respeto de la dignidad de la persona humana, como norma rectora del orden constitucional.

En una visión de conjunto, el Estado chileno cuenta con un sistema de seguridad social en que aquél asume un papel de garante y fiscalizador por disposición constitucional, pero la gestión de

22 El Art. 20 Inc, $1^{\circ} \mathrm{CPR}$ prescribe: "El que por causa de actor u omisiones arbitrarios o ilegales sufra privación, perturbación o amenaza en el legítimo ejercicio de los derechos y garantías establecidos en el artículo 19. . . podrá ocurrir por sí o por cualquiera a su nombre, a la Corte de Apelaciones respectiva, la que adoptará de inmediato las providencias que juzgue necesarias para restablecer el imperio del derecho y asegurar la debida protección del afectado, sin perjuicio de los demás derechos que pueda hacer valer ante la autoridad o los tribunales correspondientes./" 
los riesgos y contingencias sociales la comparte con personas privadas, las que han asumido un papel preponderante en materia de previsión social, salud, cesantía o desempleo y accidentes del trabajo y enfermedades profesionales.

Limitando estos comentarios a un nivel de generalidad acorde al objetivo de este trabajo, se puede decir que dicha gestión asume un carácter mixto -público y privado, en el cual lo público se aplica a las prestaciones que perciben ciertos grupos de presión importantes y cotizantes del sistema previsional antiguo basado en el reparto. Por lo mismo, la solidaridad suele estar presente y en gran medida en este sistema público bajo la forma de un aporte fiscal, pero lo está mucho menos en el sistema privado a que está adscrita la gran mayoría de las personas, especialmente los trabajadores dependientes del sector privado y los funcionarios públicos de la administración civil del Estado.

\subsection{Regímenes jurídicos de gestión pública y de inspiración solidaria}

El régimen previsional de los integrantes de las Fuerzas Armadas y de Orden y Seguridad Pública, constituye un caso de gestión pública de los riesgos y contingencias sociales. Ellos han contado con un régimen basado en el reparto desde el siglo pasado; de hecho, fueron excluidos deliberadamente del "Nuevo Régimen de Pensiones" basado en la capitalización individual en 1980.

El de los integrantes de las Fuerzas Armadas está en manos de la Caja de Previsión de la Defensa Nacional, que es una institución autónoma, con patrimonio y personalidad jurídica propia que está bajo la supervigilancia del Ministerio de la Defensa Nacional, mientras que el de las Fuerzas de Orden y Seguridad Pública está en manos de la Dirección de Previsión de Carabineros de Chile, que es un organismo descentralizado, con patrimonio y personalidad jurídica propia, dependiente del Ministerio del Interior y Seguridad Pública desde 2011.

Este régimen cubre las contingencias de retiro, montepío, invalidez, desahucio, fallecimiento y otros beneficios menores del personal respectivo, bajo un esquema de universalidad objetiva y subjetiva. Consta de un componente contributivo y otro no contributivo, lo que se traduce en que los afiliados deben contribuir con un porcentaje variable de sus salarios o pensiones mensuales imponibles, dependiendo del beneficio de que se trate, y el Estado aporta la diferencia, en forma directa y bajo la forma de un aporte fiscal previsto en la Ley de Presupuestos de la Nación, lo que permite enterar los diversos fondos comunes que financian el pago de las prestaciones sociales.

El impacto de lo anterior no es menor, pues un estudio reciente de la Dirección de Presupuestos del Ministerio de Hacienda señala que las cotizaciones de los afiliados a este sistema financian alrededor del 10\% de los gastos totales, por lo que la diferencia restante se cubre mediante el aporte fiscal por el Estado, generando un déficit de alrededor del 1\% del Producto Interno Bruto (PIB) en 2011 (Benavides \& Jones, 2012, p. 7). Por esto el Estado viene en auxilio solidario de este grupo de presión mediante un aporte fiscal bastante generoso, a la luz de los beneficios que otorga dicho régimen, el cual es extraído de los Fondos Generales de la Nación.

En el caso de los cotizantes del régimen previsional antiguo basado en el reparto, este grupo está definido claramente en su extensión y dice relación con quienes cotizaban en las antiguas 
Cajas de Previsión (quince cajas app.) o en el Servicio de Seguro Social y no se afiliaron al nuevo régimen previsional en 1980, permaneciendo en el régimen previsional antiguo desde entonces. Estas personas y sus empleadores cotizaban a un fondo común, administrado por alguno de dichos organismos, al cual el Estado aportaba una contribución fiscal anual, para efectos del pago de las prestaciones respectivas, la que aumentó su cuantía en el tiempo y generó déficits crecientes de operación. Por esta razón, estos organismos de seguridad social fueron integrados y sus funciones traspasadas al Instituto de Normalización Previsional entre 1982 y 1988, asumiendo el Estado el financiamiento de los déficits de operación de cada régimen previsional.

Actualmente, la administración de los beneficios de este grupo de personas está en manos del Instituto de Previsión Social, que es un servicio público funcionalmente descentralizado, con personalidad jurídica y patrimonio propio, dependiente del Ministerio del Trabajo y Seguridad Social, creado en 2008, el cual administra dichos regímenes previsionales, conforme a los Arts. 53 y $55 \mathrm{~N}^{\circ} 6$ de la Ley $N^{\circ} 20.255$, del mismo año. Este servicio público entrega a los beneficiarios prestaciones por vejez, antigüedad, invalidez y sobrevivencia, de acuerdo las condiciones y circunstancias del organismo a que estaban afiliados originalmente. En este caso, el Estado también auxilia solidariamente a este grupo de personas, pues el déficit financiero que genera la operación de su régimen previsional haría imposible el pago de las prestaciones sociales.

Lo público y lo solidario también están presentes en las prestaciones que se otorgan a personas de bajos ingresos económicos, que carecen de capacidad de ahorro o éste es insuficiente, para procurarse una pensión de vejez o invalidez. La administración de las prestaciones respectivas, bajo el denominado Sistema Solidario de Vejez e Invalidez, corresponde al Instituto de Previsión Social, aludido supra, para lo cual tiene atribuciones para otorgarlas, extinguirlas, modificarlas o suspenderlas, de acuerdo a la ley. Este servicio público está sujeto a la supervigilancia y fiscalización de la Superintendencia de Pensiones.

El Sistema Solidario de Vejez e Invalidez constituye el denominado "pilar solidario", creado por la reforma de la Ley $N^{\circ} 20.255$, de 2008. La creación de esta institución obedeció a la exclusión creciente de trabajadores del "Nuevo Régimen de Pensiones" basado en la capitalización individual, como asimismo a la pérdida de la capacidad de ahorro previsional de muchos afiliados a este régimen.

En tal sentido, el análisis efectuado por la comisión asesora del gobierno, denominada "Comisión Marcel", diagnóstico la existencia de grupos de cotizantes que carecían de cotizaciones previsionales ininterrumpidas, producto de cambios tecnológicos o económicos que impactaban el mercado del trabajo; trabajadores informales que no efectuaban cotizaciones previsionales para financiar una pensión de vejez; grupos desaventajados que cotizaban menos que otros, producto de circunstancias especiales o laborales, v. gr. mujeres, jóvenes, trabajadores de temporada, pensionados de diversos sistemas que percibían pensiones de vejez ínfimas, etc., todo lo cual redundaba en que una mayoría de la población, especialmente la laboralmente activa, carecería de pensión alguna en el futuro o contaría con una pensión de vejez ínfima para sustentar un nivel de vida digno (Arellano, 2012, pp. 192 y ss.; Consejo Asesor Presidencial para la Reforma Previsional, 2006, pp. 16 y ss). 
En consecuencia, existía una falla evidente en la universalidad de la seguridad social, más allá de lo que dijeran los textos legales de la época que contemplaban pensiones mínimas garantizadas de bajo monto y pensiones asistenciales que dependían del financiamiento y disponibilidad fiscal. Por lo demás, el Comité de Derechos Económicos, Sociales y Culturales ya había recomendado al gobierno, en 2004, adoptar

... medidas efectivas para que todos los trabajadores gocen de prestaciones de seguridad social adecuadas, con inclusión de medidas especiales para prestar asistencia a los grupos que actualmente no pueden hacer cotizaciones al régimen privado de seguridad social, prestando particular atención a la situación de desventaja de la mujer y del gran número de trabajadores temporales y de temporada y de trabajadores de la economía no estructurada (Oficina del Alto Comisionado de las Naciones Unidas para los Derechos Humanos, 2004, pp. 67 y ss).

Pese a lo discutible del tema, Arellano (2012, p. 215) sostiene que la creación del Sistema Solidario de Vejez e Invalidez no generó un sistema multi-pilar en la seguridad social chilena, sino que afirmó la existencia de un sistema de un solo pilar que consta de dos componentes, a saber, uno de carácter contributivo basado en la capitalización individual de las personas y otro de carácter no contributivo basado en el aporte fiscal del Estado y que comienza a operar cuando el componente contributivo no existe o es insuficiente.

El Sistema Solidario de Vejez e Invalidez consta de pensiones básicas solidarias de vejez e invalidez y de aportes previsionales solidarios de vejez e invalidez, todos los cuales son financiados mediante un aporte estatal con cargo a Fondos Generales de la Nación.

La pensión básica solidaria de vejez ${ }^{23}$ se otorga a quienes no tienen derecho a pensión en régimen previsional alguno, hayan cumplido sesenta y cinco años de edad; integren un grupo familiar perteneciente al 60\% más pobre del país y acrediten residencia, continua o discontinua, en el territorio nacional por no menos de veinte años, contados desde que el peticionario haya cumplido los veinte años de edad y, en todo caso, por un lapso no menor a cuatro años de residencia en los últimos cinco años inmediatamente anteriores a la fecha de presentación de la solicitud, con excepción de las personas carentes de recursos, para quienes el plazo se cuenta desde su fecha de nacimiento, como disponen los Arts. $3^{\circ}$ ss. de la ley referida.

La pensión básica solidaria de invalidez, en tanto, se otorga a quienes sean declaradas inválidas conforme a la ley; no tengan derecho a pensión en algún régimen previsional; tengan entre dieciocho y sesenta y cinco años de edad; acrediten residencia en el territorio nacional por no menos de cinco años en los seis últimos años inmediatamente anteriores a la presentación de la solicitud respectiva e integren un grupo familiar perteneciente al 60\% más pobre de la población nacional, según los Arts. 16 ss. de la ley.

El aporte previsional solidario de vejez se otorga a quienes se encuentran pensionados en virtud del nuevo régimen de pensiones (excepcionalmente a quienes gozan de pensiones de sobrevi-

23 A la fecha, el ingreso mínimo mensual fijado por ley es de aproximadamente US\$382.-, para trabajadores entre 18 y 65 años de edad. La pensión básica solidaria de vejez asciende aproximadamente a \$132.- mensuales. 
vencia conforme a la ley de accidentes del trabajo y enfermedades profesionales) y cuya pensión base sea inferior al valor de la pensión máxima con aporte solidario, por lo que tiene por objeto proveer de un incremento a quienes gozan de bajas pensiones, acorde a los Arts. 9 ss. de la ley.

El aporte previsional solidario de invalidez se otorga a quienes hayan sido declarados inválidos, total o parcialmente, encontrándose afiliados al nuevo régimen de pensiones y cuya pensión de invalidez sea inferior a la pensión básica solidaria de invalidez, de acuerdo a los Arts. 20 ss. de la ley.

Por cierto, la creación de este Sistema Solidario de Vejez e Invalidez ha permitido extender sobre bases solidarias la universalidad - objetiva y subjetiva, del régimen previsional chileno relativo a las pensiones de vejez, invalidez y sobrevivencia, pero con un carácter tan básico, a lo menos en cuanto a su monto, que se puede cuestionar la integridad o suficiencia de las prestaciones del mismo. Debe recordarse, en este punto, que la Resolución señala en su Conclusión 13. que “. . los sistemas de pensiones obligatorios deben garantizar un nivel de prestaciones adecuados", el que no parece cumplirse en el caso de las denominadas pensiones solidarias.

\subsection{Régimen jurídico de gestión preferentemente privada y de inspiración solidaria}

Una gestión preferentemente privada y sobre bases solidarias es la que inspira el seguro social contra riesgos de accidentes del trabajo y enfermedades profesionales, creado por la Ley $\mathrm{N}^{\circ}$ 16.744, de 1968 y que ha sido extendido a grupos de afiliados no previstos originalmente, v. gr. campesinos asignatarios de tierras, suplementeros, estudiantes en práctica profesional, pequeños mineros artesanales, trabajadores independientes, etc. Este régimen fue creado para asistir a quienes sufriesen accidentes laborales o adquiriesen enfermedades profesionales en el desarrollo de sus labores, como asimismo para propender a una disminución en la ocurrencia de estos riesgos sociales, para lo cual el legislador acudió al auto-interés de quienes lo financian principalmente -los empleadores, toda vez que vinculó la cuantía de las cotizaciones adicionales pagadas por éstos con la tasa de frecuencia de accidentabilidad.

Este seguro social protege a todos los trabajadores por cuenta ajena, incluyendo servidores domésticos y aprendices; funcionarios públicos; estudiantes que desarrollan labores que signifiquen ingresos para sus planteles y trabajadores independientes y trabajadores familiares, conforme al Art. $2^{\circ}$ de la ley citada.

Los riesgos y contingencias sociales cubiertas son los accidentes del trabajo y las enfermedades profesionales, contemplándose el otorgamiento de prestaciones médicas hasta la completa curación de la víctima o mientras subsistan los síntomas de las secuelas causadas por la enfermedad o accidente; prestaciones por incapacidad temporal que se traducen en el pago de subsidios al accidentado o enfermo profesional; prestaciones por invalidez, parcial o total, que se traducen en el pago de indemnizaciones que varían en su monto en función de la pérdida de la capacidad de ganancia de la víctima de un accidente o enfermedad profesional y prestaciones por supervivencia consistentes en el pago de pensiones de supervivencia, las que al igual que los subsidios, son incompatibles con las similares que contemplan otros regímenes previsionales, acorde a los Arts. 29 ss. de la ley. En todo 
caso, las pensiones de supervivencia contempladas en la ley son de bajo monto, por lo que queda la duda sobre la suficiencia o integridad de estas prestaciones de seguridad social.

Este régimen de la seguridad social es financiado casi íntegramente mediante un mecanismo contributivo, el que es cargo del empleador. Este debe cotizar el 0,90\% de las remuneraciones mensuales imponibles de cada trabajador, a la que se puede agregar una cotización adicional por hasta el 3,4\% de dichas remuneraciones en función del riesgo de la actividad o empresa de que se trate, como indica el Art. 15 de la ley. En cambio, los trabajadores -beneficiarios directos del seguro, no deben efectuar contribución financiera alguna para este seguro.

Interesantemente, el Art. 16 de la ley autoriza a los empleadores a solicitar la reducción o eximición de esta cotización adicional si acreditan haber implantado medidas de prevención que rebajen apreciablemente los riesgos de accidentes del trabajo o enfermedades profesionales, habiendo alcanzado niveles óptimos de seguridad de acuerdo a los organismos administradores del seguros. Por el contrario, quienes no ofrezcan condiciones satisfactorias de seguridad y/o higiene, o no implanten las medidas de seguridad que el organismo competente les ordene, deben pagar la totalidad de la cotización adicional con un recargo de hasta un 100\%, como indica el Art. 16 de la ley. Por esta razón, el legislador acudió al auto-interés de quienes financian este régimen, lo que ha contribuido en su mantención hasta la actualidad.

En la administración de este seguro se advierte una mixtura pública-privada, pero la gestión efectiva del mismo es preferentemente privada. De acuerdo al Art. $8^{\circ}$ ss. de la ley, la administración corresponde actualmente al Instituto de Seguridad Laboral, que es un servicio público dependiente del Ministerio del Trabajo y de Seguridad Social y sujeto a la fiscalización de la Superintendencia de Seguridad Social. ${ }^{24}$

No obstante, la misma ley autoriza que la administración del seguro pueda ser efectuada, en su lugar, por Mutualidades de Empleadores, respecto de los trabajadores dependientes de empleadores adheridos a ellas, como acontece en la mayoría de los casos. Estos organismos son corporaciones privadas, sin fines de lucro, que tienen por objeto específico administrar el seguro social mencionado y su existencia puede ser aprobada por el Presidente de la República, previo cumplimiento de los requisitos legales; de hecho, todas ellas habían sido creadas con anterioridad a la dictación de esta ley y su funcionamiento satisfactorio aconsejó su mantención, por parte del Poder Legislativo en 1968.

Sin perjuicio de lo anterior, la ley autoriza que empresas que cuentan con dos mil o más trabajadores, un capital y reservas de gran consideración, Comités Paritarios (trabajadores-empleador) de Higiene y Seguridad, posean servicios médicos internos adecuados y desarrollen actividades permanentes y efectivas de prevención de enfermedades profesionales y accidentes, entre otros, puedan solicitar se les confiera la calidad de Administradoras Delegadas de este seguro social respecto de sus trabajadores. Tanto las Mutualidades de Empleadores, como las Administradoras Delegadas del

\footnotetext{
24 La supervigilancia y fiscalización de la prevención, higiene y seguridad en los sitios de trabajo corresponde a los Servicios de Salud, de acuerdo al Art. 65 de la Ley $N^{\circ} 16.744$ y si se trata de una faena minera, entonces tiene competencia también el Servicio Nacional de Geología y Minería, acorde al Art. 2 № 8 Decreto Ley Nº 3.525, de 1980.
} 
seguro, están sujetas a la fiscalización de la Superintendencia de Seguridad Social, pudiendo considerarse expresión del principio de subsidiariedad.

Ahora bien, los empleadores participan de la administración del seguro a través de las Mutualidades de Empleadores y las Empresas Administradoras Delegadas del seguro referido, cuando han sido autorizados para ello, y además en la prevención de riesgos de accidentes del trabajo y enfermedades profesionales a través de tres representantes en los Comités Paritarios de Higiene y Seguridad, creados por la ley en todas las empresas con más de veinticinco trabajadores.

En cambio, los beneficiarios directos del seguro -los trabajadores, no participan de su administración propiamente tal, sino sólo en la prevención de riesgos de accidentes del trabajo y enfermedades profesionales, a través de los Comités Paritarios de Higiene y Seguridad, para cuyo efecto deben elegir tres representantes a cada uno de dichos comités, los que gozan de fuero laboral mientras ejercen el cargo. Por esto la Conclusión 4. de la Resolución, que preceptúa que los regímenes deberían administrarse ". . con fuerte participación de los interlocutores sociales", es cumplida sólo parcialmente.

\subsection{Régimen jurídico de gestión privada y de inspiración solidaria}

Una gestión propiamente privada y sobre bases solidarias de un riesgo y contingencia social lo constituye el régimen del seguro de desempleo o cesantía. La Ley № 19.728, de 2001, creó el seguro de desempleo, el que es administrado por una persona privada, con fines de lucro, que desarrolla una actividad empresarial y que se denomina Sociedad Administradora.

La Sociedad Administradora es una sociedad anónima, chilena o agencia de una extranjera constituida en Chile, cuyo giro único y exclusivo consiste en administrar los dos fondos de desempleo o cesantía que contempla la ley, a saber, el Fondo de Cesantía y el Fondo Solidario de Cesantía. Esta sociedad es aquella que resulte adjudicada en la licitación pública del contrato de administración del seguro respectivo, convocado por los Ministerios del Trabajo y Previsión Social y de Hacienda.

Cabe agregar que dicha sociedad tiene el carácter de administradora única del seguro durante la vigencia del contrato de administración y respecto de todos los trabajadores dependientes que inicien o reinicien actividades con posterioridad a la vigencia de la ley, por regla general, por lo que no existe libertad de contratación para los beneficiarios. La supervigilancia, fiscalización y control del funcionamiento de la Sociedad Administradora corresponde a la Superintendencia de Seguridad Social.

Conforme al Art. $5^{\circ}$ de la ley, el financiamiento del seguro es tripartito, lo que introduce una dosis de solidaridad en el régimen jurídico respectivo. Tratándose de trabajadores con contratos indefinidos, cada trabajador debe cotizar un $0,6 \%$ de sus remuneraciones mensuales imponibles y el empleador debe cotizar el 1,6\% de estas últimas; en cambio, tratándose de trabajadores con contrato a plazo fijo o por obra, trabajo o servicio determinado, el empleador debe cotizar un 2,8\% de las remuneraciones mensuales imponibles de cada trabajador, estando el trabajador dispensado de efectuar cotización alguna. 
Estas cotizaciones van destinadas a la cuenta individual de cesantía de cada trabajador afiliado al seguro y los recursos acumulados en ella son propiedad de este último. Estas cuentas son administradas por la Sociedad Administradora, quien puede cobrar una comisión uniforme por dicha administración, la que comprende el cobro de las cotizaciones, su inversión en instrumentos financieros de renta fija para asegurar una rentabilidad y el otorgamiento de las prestaciones respectivas, entre otros.

Asimismo, existe un Fondo de Cesantía Solidario, el que complementa el ahorro individual de los trabajadores para el caso que aquél sea insuficiente para el pago del seguro y constituye un fondo de reparto al que aportan los empleadores y el Estado. Este fondo no pertenece a ningún trabajador individual y el Estado aporta anualmente al mismo un total de 225.792 Unidades Tributarias Mensuales. ${ }^{25}$ El empleador, por su parte, aporta a este fondo un $0,8 \%$ o un $0,2 \%$ de las remuneraciones mensuales imponibles de cada trabajador, dependiendo del tipo de contrato de trabajo, esto es, si es indefinido o no. Este fondo solidario es administrado por la Sociedad Administradora, con las mismas atribuciones y deberes que existen para el fondo anterior, incluido el cobro de comisiones uniformes por su administración.

El acceso del trabajador a este fondo exige, entre otros requisitos, asistir mensualmente a una Oficina Municipal de Intermediación Laboral, a cargo del gobierno local respectivo, para acceder a empleo o capacitación que estuviere disponible, debiendo inscribirse en la Bolsa Nacional de Empleo que crea la ley, lo que está acorde a la Conclusión 7. de la Resolución; además, el cobro de las prestaciones respectivas exige búsqueda efectiva de empleo, estableciéndose causales de rechazo o cese de pago de prestaciones cuando ello no ocurre.

Los beneficiarios del seguro pueden girar sumas de dinero en contra de los saldos acumulados en sus cuentas individuales, en base a cierto porcentaje de remuneraciones de un periodo y en contra del Fondo de Cesantía Solidario cuando han agotados los fondos de sus cuentas individuales y cumplan los demás requisitos legales. Sin embargo, los beneficiarios que hagan uso del Fondo de Cesantía Solidario obtendrán el pago de sus cotizaciones previsionales de vejez, con cargo a dicho fondo y exento del pago de comisiones, a contar del $1^{\circ}$ de agosto de 2015.

Cabe puntualizar que los beneficiarios tampoco participan en forman alguna de la administración de este seguro, por lo que el principio de participación y la Conclusión 4. de la Resolución resultan frustradas en su aplicación real. De hecho, ellos forman parte de un órgano semi-paritario de carácter consultivo, denominado Comisión de Usuarios, que es presidido por un académico, el que tiene por objeto conocer los procedimientos y criterios de administración y pago de prestaciones por la Sociedad Administradora, pudiendo concurrir con derecho a voz a la junta de accionistas de aquélla.

Resulta curiosa este régimen jurídico, desde un punto de vista conceptual, pues se trata de un seguro regido por normas de derecho público, con inspiración solidaria y administrado por una persona privada con fines de lucro. En este régimen difícilmente se cumple la integridad o suficiencia e igualdad de la seguridad social, desde que las sumas que podrán girar los beneficiarios irán dismi-

$\overline{25}$ Aproximadamente US\$15.000.000.- anuales.

EJJL 
nuyendo en la medida que agoten su cuenta individual, como tampoco la universalidad subjetiva, ya que categorías completas de trabajadores están excluidos de este seguro, como los funcionarios públicos, trabajadores pensionados y trabajadores de casa particular, entre otros. Tampoco se cumple la participación de los beneficiarios y de los cotizantes en la gestión del seguro. Finalmente, la opción por una persona privada con fines de lucro, desarrollando una actividad propiamente empresarial, constituye una proyección -meramente presunta, de la forma particular como se lee el principio de subsidiariedad en materia económico-social.

\subsection{Régimen jurídico de gestión privada y de inspiración preferentemente no solidaria}

Una gestión privada de riesgos y contingencias sociales y de inspiración preferentemente no solidaria caracteriza al régimen jurídico de las pensiones de vejez, invalidez y sobrevivencia, creado por el Decreto Ley $N^{\circ} 3.500$, de 1980, que constituye el denominado "Nuevo Régimen de Pensiones".

Este régimen se basa en la capitalización individual de los beneficiarios, quienes deben cotizar un porcentaje de sus remuneraciones y rentas mensuales imponibles en una Administradora de Fondos de Pensiones, en adelante AFP. Esta última constituye una persona privada, con fines de lucro, que desarrolla una actividad empresarial y que se constituye como una sociedad anónima cuyo único giro consiste en administrar fondos de pensiones y otorgar las prestaciones y beneficios respectivos a sus afiliados, para lo cual debe mantener un patrimonio y contabilidad separados para los fondos de pensiones que administra, los que de manera alguna son de su propiedad, según los Arts. 27 y 33 del decreto ley. Además, los bienes y derechos que componen el patrimonio de dichos fondos son, por regla general, inembargables, conforme al Art. 34 del mismo cuerpo legal, contemplándose normas especiales para su liquidación, en caso de quiebra de una AFP, en los Arts. 43 ss. del mismo. Las AFP están sujetas a la supervigilancia y fiscalización de la Superintendencia de Pensiones, como señalado supra.

Los afiliados a este régimen son todos los trabajadores que hayan iniciado su vida laboral con posterioridad a la entrada en vigencia de este decreto ley, quienes están adscritos a aquél y a alguna de las AFP existentes. Como una forma de introducir mayor competencia entre las AFP y disminuir las barreras de entrada a este giro, la ley autorizó a las compañías de seguros para constituir AFP y, dado el valor de las comisiones que estas últimas cobran a sus afiliados, determinó que se licitara públicamente la afiliación de los trabajadores que ingresaran al mercado del trabajo luego de 2008, de manera de adjudicar el contrato respectivo a la AFP que ofertara las menores comisiones del mercado, como ha sucedido desde entonces, lo que no se ha traducido necesariamente en una mayor rentabilidad de sus fondos de pensiones.

Para quienes fueron obligados a afiliarse a este régimen jurídico desde sus inicios, la libertad de contratación fue eliminada absolutamente por el legislador, pero conservaron - y conservan, la libertad para elegir la AFP correspondiente, el fondo de pensiones en que quieren que sus ahorros se inviertan y de cambiarse -más adelante, de AFP, si así lo desean: en cambio, tratándose de quienes 
se afiliaron después de 2008, debieron hacerlo obligatoriamente a la AFP que ganó la licitación pública, mencionada supra, conservando las restantes libertades (Arellano, 2012, p. 314).

Cada afiliado hombre menor de sesenta y cinco años de edad y mujer menor de sesenta años de edad, debe sufragar el costo de su cotización para pensión de vejez, que asciende a un 10\% de su remuneración y renta mensual imponible, con un límite de 60 Unidades de Fomento, ${ }^{26}$ la que es depositada en una cuenta de capitalización individual en una AFP, previo descuento por el empleador en el caso de trabajadores dependientes. Debido a que las cotizaciones son de propiedad del cotizante, el empleador puede ser apremiado por la Justicia, en caso de no enterar dichas cotizaciones en la AFP, pudiendo incluso incurrir en un delito penal de estafa, conforme a la Ley $\mathrm{N}^{\circ} 17.322$, de 1970, ya que las cotizaciones son de propiedad del cotizante.

Los afiliados que desempeñan trabajos pesados deben también enterar una cotización equivalente al $2 \%$ de su remuneración mensual imponible en su cuenta de capitalización individual, debiendo el empleador aportar otro $2 \%$ para este efecto, porcentajes que pueden reducirse a un $1 \%$ por determinación de la Comisión Ergonómica Nacional, en razón del menor desgaste relativo producido por el trabajo pesado, acorde al Art. 17 del decreto ley.

Por su parte, el empleador debe pagar una cotización adicional para el financiamiento de la AFP y la contratación de un seguro de invalidez y sobrevivencia para el afiliado desde 2008, cuyo monto fija cada AFP en forma uniforme para todos los afiliados, el que es licitado públicamente por todas las AFP. Esta cotización adicional constituye un "parpadeo" de solidaridad en un régimen jurídico cuya arquitectura es ajena a ella.

Las cotizaciones de los afiliados pueden depositarse en distintos fondos de pensiones que administra una AFP, existiendo libertad de elección de fondo por parte del afiliado, excepto para los varones que cumplan cincuenta y cinco años de edad y las mujeres que cumplan los cincuenta años de edad, quienes no pueden optar por invertir sus cotizaciones en el fondo previsional de mayor riesgo - el Fondo A, de acuerdo al Art. 23 Inc. $3^{\circ}$ del decreto ley referido.

Sobre este punto, cabe precisar que cada AFP administra cinco fondos de pensiones en grado ascendente de riesgo de inversión, denominados Fondos A, B, C, D y E, los que están invertidos en diferentes instrumentos de inversión, previamente determinados por la autoridad fiscalizadora, a objeto de reducir el riesgo de pérdida. Cabe agregar que las AFP invierten las cotizaciones en instrumentos de renta fija o variable, nacionales o extranjeros, con distintos grados de riesgo, de acuerdo a las instrucciones recibidas de sus afiliados. Asimismo, las AFP deben garantizar cierta rentabilidad mínima de los fondos para el afiliado, que se computa en términos anualizados y por periodos de 36 meses, conforme al art. 37 del decreto ley; en caso contrario, deben responder y enterar la rentabilidad mínima legal echando mano a una reserva especial, denominada Encaje, equivalente al 1\% de cada fondo, según el Art. 40 del mismo cuerpo legal. Todo esto debería constituir un incentivo para la educación financiera de los afiliados, pero no existe evidencia que ella sea muy extendida entre aquéllos.

$\overline{26}$ Aproximadamente, la renta mensual imponible con dicho límite asciende a US\$963.- 
Conforme al Art. 61 del decreto ley, los afiliados que cumplan los requisitos para pensionarse por vejez (sesenta años las mujeres y sesenta y cinco años los varones), los afiliados declarados inválidos totales y aquellos declarados inválidos parciales, pueden disponer del saldo de su cuenta de capitalización individual para constituir una pensión. ${ }^{27}$ Para ello, pueden optar por alguna de las siguientes modalidades, a saber: renta vitalicia inmediata; renta vitalicia inmediata con retiro programado; renta temporal con renta vitalicia diferida, o retiro programado, indica la misma norma legal. Para estos efectos, los Arts. 62 ss. del decreto ley definen estas modalidades de pensión de la manera siguiente:

a) Renta vitalicia inmediata: es aquella que el afiliado contrata con una compañía de seguros de vida, por la cual ésta se obliga a pagar una renta mensual a aquél, a partir de la celebración de contrato respectivo y hasta su fallecimiento, debiendo pagar las pensiones de sobrevivencia a sus beneficiarios;

b) Renta vitalicia inmediata con retiro programado: es la renta vitalicia inmediata que, con una parte del saldo de la cuenta de capitalización individual, el afiliado contrata con una compañía de seguros de vida, acogiéndose con la parte restante a la modalidad de retiro programado;

c) Renta temporal con renta vitalicia diferida: es el pago de una renta mensual que el afiliado contrata con una compañía de seguros de vida, a partir de una fecha futura, conservando en su cuenta de capitalización individual los fondos suficientes para obtener de su AFP el pago de una renta temporal, durante el periodo que medie entre la fecha en que se ejerce la opción por esta modalidad y la fecha en que la renta vitalicia diferida deberá comenzar a ser pagada por la compañía de seguros antedicha;

d) Retiro programado: es la modalidad que obtiene el afiliado con cargo al saldo que mantiene en su cuenta de capitalización individual, como resultado de retirar anualmente la cantidad expresada en Unidades de Fomento que resulte de dividir cada año el saldo efectivo de su cuenta de capitalización individual por el capital necesario para pagar una unidad de pensión al afiliado y, fallecido éste, a sus beneficiarios.

Las AFP tienen derecho a cobrar una comisión mensual por la administración de los fondos de pensiones de cada cotizante, que se descuenta de la cuenta de capitalización individual o de los retiros, la que resulte exigible independientemente de la ganancia o pérdida que experimenten los fondos de pensiones de los cotizantes (esto es, "la casa nunca pierde". . .) De hecho, las AFP sólo responden de los perjuicios causados a los afiliados en sus cuentas de capitalización individual, producto del incumplimiento oportuno de sus obligaciones o de las instrucciones dadas por el afiliado

\footnotetext{
27 De acuerdo a la Asociación Gremial de AFP (2012), las pensiones por invalidez total ascienden al 70\% del promedio de las remuneraciones recibidas en los últimos 10 años por el afiliado, mientras que las pensiones por invalidez parcial ascienden a un $50 \%$ de dicho promedio, en ambos debidamente actualizadas de acuerdo a la inflación, existiendo normas especiales para el caso de desempleo en los doce meses anteriores a la declaración de invalidez.
} 
en ejercicio de sus derechos legales, según el Art. 39 del decreto ley, como asimismo en caso de no obtener la rentabilidad mínima legal, conforme al Art. 40 del mismo.

Todo esto hace que este régimen sea caro para los afiliados, no obstante las medidas adoptadas para estimular la competencia entre las AFP, ya que la rentabilidad de los fondos de pensiones tampoco es demasiado elevada y las pérdidas bursátiles producidas en situación de crisis externa generalizada, v. gr. crisis sub-prime, pueden tener efectos devastadores en los fondos acumulados por afiliados que están próximos a retirarse, pese a todos los resguardos adoptados por el legislador y la administración fiscalizadora. Así, por lo que las prestaciones que otorga este régimen son inseguras, contrariamente a lo requerido por la Conclusión 4. de la Resolución, por lo que no debe extrañarnos que Arellano (2012) sugiera que los fondos de pensiones garantizan una prestación más indeterminada que otros sistemas, $y$, en tal sentido, sostenga que no existe equivalencia matemática entre las comisiones y las prestaciones que pueda otorgar una AFP, pese a la conmutatividad aparente entre las obligaciones a que da origen la afiliación a esta última (pp. 256-277 y ss). En el mismo sentido, Gumucio (2009, p. 170) precisa que este régimen tiene contribuciones definidas, pero prestaciones inciertas, contrariamente a lo exigido por el Convenio $N^{\circ} 102$ de la OIT. Sin duda, lo anterior pasa por encima de lo que dispone pertinentemente la Observación General, la que dice en su $\$ 22$ que “. . cuando una persona cotiza a un plan de seguridad social que ofrece prestaciones para suplir la falta de ingresos, debe haber una relación razonable entre los ingresos, las cotizaciones abonadas y la cuantía de la prestación pertinente" (Comité de Derechos Económicos, Sociales y Culturales, 2008, p. 8).

Por cierto, esto no implica desconocer el hecho que el régimen descrito supra permitió la creación de un mercado secundario en una época de profunda recesión económica, como el de principios de la década de 1980, pero la persistencia de la arquitectura original del mismo promueve la inquietud sobre la finalidad última de aquél, dados sus efectos negativos en el tiempo y que abonaron la reforma de la Ley $N^{\circ} 20.255$, de 2008, que creó el Sistema de Pensiones Solidarias, referido supra. ${ }^{28}$ Y es que la Observación General interpela, en este punto, a los Estados partes del PIDESC, al recordarles que al interpretar los diferentes aspectos del derecho fundamental a la seguridad social "[...] debe tenerse presente que conviene considerar a la seguridad social como un bien social y no principalmente como una mercancía o un mero instrumento de política económica o financiera" (Comité de Derechos Económicos, Sociales y Culturales, 2008, p. 4). Por las razones expuestas, no se está en presencia de un seguro social, como lo dispone el Art. 9 PIDESC.

El mismo punto efectuó en una obra reciente el ex-Ministro del Tribual Constitucional, Profesor Dr. Mario Fernández-Baeza, quien señaló con agudeza el problema planteado por este régimen jurídico, que precariza aún más el derecho fundamental a la seguridad social en la vida real de los afiliados, para lo cual empleó la siguiente reflexión:

El derecho a la seguridad social. . . se enfrenta en los próximos años por primera vez a la afluencia masiva de pagos de pensiones, que pondrá a prueba el sistema de capitalización que reemplazó al sistema de reparto en 1980 [...] hasta los partida-

\footnotetext{
28 A la fecha, los fondos de pensiones acumulados ascienden a US\$162.000.000.000.-, de los cuales un 46\% aproximadamente se encuentra invertido en dólares estadounidenses en el extranjero (Mendoza, 2015).
} 
rios del sistema se encuentran abogando por modificaciones del modelo, aunque la mayoría sin alterar el sistema de capitalización, especialmente por la incidencia que el monto de ahorros acumulados tiene en la economía del país, especialmente en el sector financiero externo. Pero es evidente que el monto esperable de las pensiones que se han empezado a pagar son mucho menores que las esperadas y muy altos los márgenes de utilidades de las Administradoras de Fondos de Pensiones (AFP), así como los gastos de administración del sistema (Fernández, 2013, p. 368).

Al igual que en el seguro de desempleo o cesantía, los beneficiarios de este régimen no participan en su administración en forma alguna y sólo integran recientemente, por medio de un par de representantes, una Comisión de Usuarios del Sistema de Pensiones, compuesta por cinco miembros, que tiene por función informar a la Subsecretaría de Previsión Social y otros organismos públicos competentes, sobre la evaluación que sus representados tienen acerca de dicho sistema y proponer estrategias de educación y difusión del mismo, según el Art. 43 de la Ley N²0.255, de 2008.

Este último cuerpo legal, precisamente, introdujo diversas modificaciones a este régimen, dados los efectos negativos del mismo, con el objeto de enfrentar la falla de universalidad del régimen jurídico en comento, entre las cuales pueden destacarse la creación del Sistema Solidario de Vejez e Invalidez, descrito supra, como asimismo otras medidas tendientes a hacer universal el régimen indicado y cuya eficacia - menor o mayor, se conocerá en los años venideros, a saber: inclusión de los trabajadores independientes en el nuevo régimen de pensiones, incluido el Sistema Solidario antedicho, la que es cautelada por la vía tributaria; introducción de normas para equidad de género, tendientes a incorporar, mantener y beneficiar a las mujeres adscritas al régimen, las que se proyectan en términos de compensación previsional por divorcio o nulidad de matrimonio y licitación separada por género del seguro de invalidez y sobrevivencia; creación de un aporte fiscal por natalidad para las mujeres que cotizan; creación de subsidios para la afiliación de trabajadores jóvenes; admisión de cotización por terceras personas (cónyuge, por ejemplo), por parte de afiliados; incorporación del cónyuge varón a las pensiones de sobrevivencia; mejoramiento de los mecanismos de ahorro previsional voluntario en AFP y otras entidades privadas, como forma de ahorro previsional distinto al obligatorio; extensión del seguro de invalidez y sobrevivencia hasta los sesenta y cinco años de edad para las mujeres, como una forma de incentivarlas a jubilarse más tarde; creación del ahorro previsional colectivo para grupos de trabajadores con un mismo empleador, financiado por este último y el trabajador; creación de nuevos servicios públicos fiscalizadores y de educación previsional, entre muchas otras.

Esto sugiere que el régimen de pensiones de vejez, invalidez y sobrevivencia, creado en 1980, tiene déficits normativos a la luz del derecho internacional de la persona humana incorporado al texto constitucional, los que derivan tanto de su diseño institucional, como de los efectos reales que ha tenido hasta la fecha.

Si bien es cierto que la reforma aprobada por la Ley $N^{\circ} 20.255$, de 2008, introdujo modificaciones al mismo, no lo es menos que los efectos de esta última reforma legal constituyen una incógnita en el largo plazo, no sólo por el apoyo administrativo creciente que requerirá su implementación en función de la universalidad subjetiva perseguida, sino también porque difícilmente reducirá la brecha generada entre los afiliados -tanto actuales como futuros, en razón de su distinta capacidad 
de ingresos económicos y, por extensión, de ahorro previsional, dado que no estamos en presencia de un seguro social propiamente tal, como lo exigen diversos instrumentos jurídicos internacionales, especialmente el PIDESC.

Aún más, la reforma legal en comento mantiene -en general, la arquitectura del régimen jurídico de pensiones de vejez, invalidez y sobrevivencia creado en 1980, la cual es casi ajena a los principios de igualdad, solidaridad, integridad o suficiencia, participación e internacionalidad, contemplados en el derecho internacional de la persona humana incorporado a la CPR. ${ }^{29}$ Y, al igual que el régimen jurídico del seguro de cesantía o desempleo, constituye expresión -presunta, de la forma particular como se lee el principio de subsidiariedad en materia económico-social, como indicado supra.

\section{Conclusión}

Desde la promulgación de la Carta Constitucional de 1925, el problema de la extensión y sustentabilidad de la seguridad social ha constituido una preocupación para la elite política y administrativa, debido a que el sistema político chileno se ha desarrollado políticamente y diversificado socialmente, incorporando nuevos grupos sociales tradicionalmente excluidos del proceso político.

La consagración tardía del derecho fundamental a la seguridad social, en 1970, y su precarización normativa en la Carta Constitucional de 1980, no son sino síntomas de este problema político innegable, que se traduce en cómo brindar protección jurídica y económica a un número creciente de personas que enfrentan actualmente riesgos y contingencias sociales por razones diversas, $\mathrm{v}$ gr. vejez, desempleo, enfermedad, etc., aun cuando se lo haya hecho desde concepciones ideológicas opuestas, con las consecuencias descritas supra.

El análisis del régimen jurídico de la seguridad social chilena revela que éste tiene un carácter mixto, lo que se manifiesta en la participación privada y estatal en la gestión de ciertos riesgos y contingencias sociales. Llama la atención, en esta materia, la participación privada en la gestión de los riesgos y contingencias sociales, como acontece en materia de desempleo o cesantía; vejez, invalidez y sobrevivencia de afiliados no pertenecientes a las Fuerzas Armadas y de Orden, y accidentes del trabajo y enfermedades profesionales, basados -real o presuntamente, en el principio de subsidiariedad. Esta gestión privada se efectúa mediante instrumentos y/o instituciones heterodoxas, más acordes a actividades empresariales, como se desprende del funcionamiento de personas jurídicas con fines de lucro -sociedades comerciales, encargadas de gestionar el seguro de desempleo o cesantía y las pensiones de vejez, invalidez y sobrevivencia, apartándose sensiblemente de algunos de los estándares jurídicos internacionales, especialmente de aquellos que permiten concebir a la seguridad social como un bien social propiamente tal. Sin perjuicio de lo anterior, el carácter mixto de la segu-

\footnotetext{
29 La creación de una AFP estatal, sin fines de lucro, ha sido un tema recurrente en los últimos gobiernos de centro-izquierda. El actual programa de gobierno de la Pdta. Bachelet contempla la creación eventual de una AFP estatal, cuyo proyecto es estudiado por una comisión del Ministerio del Trabajo y Previsión Social, la que debe entregar su informe en agosto de 2015. Este servicio público ampliaría la cobertura de la seguridad social, en términos de pensiones de vejez, invalidez y sobrevivencia, e introduciría mayor competencia en el sector en términos de cobro de comisiones y gastos de administración, pero no mejoraría el monto de las pensiones en el corto plazo (Barraza, 2015).
} 
ridad social chilena se evidencia en la participación estatal en la gestión de riesgos y contingencias sociales de las personas afiliadas al antiguo sistema previsional, radicado actualmente en el Instituto de Previsión Social, y de quienes integran las Fuerzas Armadas y de Orden y Seguridad Pública, todos los cuales se basan en un sistema de reparto que tiene componentes contributivos - en menor proporción, y sobre todo no contributivos de origen fiscal.

Situándonos en el plano constitucional, las normas constitucionales pertinentes aseguran este derecho fundamental en términos meramente programáticos y aspiracionales, pero sin una definición semántica mínima sobre cuál es el núcleo del derecho asegurado. Al mismo tiempo, ellas diluyen el contenido normativo de este último, produciendo su fragilidad y precarización, subordinando su eficacia a la interpretación que haga el legislador o el intérprete sobre la relación entre el Estado, la sociedad y el individuo, especialmente de la centralidad que ocupa en esta relación el principio de subsidiariedad.

Si bien la CPR entrega la regulación del ejercicio del derecho al legislador, introduciendo con ello la posibilidad de arbitrariedad legislativa, debe precisarse que es la mayoría y no la minoría la que podría estar más expuesta a este riesgo, debido al carácter contra-mayoritario y al quórum parlamentario agravado que tienen las leyes relativas a este derecho fundamental, como asimismo al hecho que éstas fueron dictadas -si no impuestas, durante el gobierno autocrático y, por ende, sin consultar la deliberación democrática ni la voluntad popular mayoritaria.

Así, la CPR asegura un derecho fundamental a la seguridad social de carácter formal, cuya única cautela judicial directa - y dudosamente eficaz, es el control de constitucionalidad de las leyes por el Tribunal Constitucional; en cambio, la gestión de las prestaciones sociales respectivas corresponde principalmente a los particulares, en lugar que al Estado, y su cautela judicial directa es la acción constitucional de protección de derechos constitucionales, por medio de la cual se invocan otros derechos que pueden comprender aspectos del derecho fundamental precitado.

Sin embargo, el método de resolución judicial de controversias y el impacto relativo de las sentencias judiciales dictadas por los jueces ordinarios, sólo producen reverberaciones entre los operadores jurídicos, pero no un cambio inmediato - si es que lo producen, en las instituciones constitucionales, ni menos alteran los efectos regresivos que algunos regímenes jurídicos han tenido en el largo plazo.

Cuando este derecho fundamental a la seguridad social es analizado desde la perspectiva del derecho internacional de la persona humana, se evidencian las omisiones y silencios del Constituyente autocrático de 1980. Esto hace que la concreción real de algunos principios rectores de la seguridad social, recogidos por el derecho internacional de la persona humana, especialmente por los instrumentos jurídicos internacionales aprobados por la OIT, e incorporados a la constitución material chilena en 1989, continúe siendo aún una meta por cumplir en forma íntegra en el sistema político chileno.

En tal sentido, existen claros déficits normativos en los principales regímenes jurídicos analizados supra, a la luz del derecho internacional de la persona humana, lo que genera dudas sobre la observancia real del respeto de la dignidad de la persona humana por parte del Estado, como nor- 
ma rectora del orden constitucional, pese a su proclamación por la CPR. Este es el caso de la universalidad, especialmente subjetiva; la integridad o suficiencia; la unidad; la igualdad; la participación y la solidaridad, cuya presencia está disminuida -si no derechamente ausente, en tales regímenes y su admisión resulta problemática - aparentemente, para la elite política y administrativa.

Este último principio es clave para dotar de fortaleza, gobernanza e identidad a un sistema de seguridad social, pues provee al sistema político de un conjunto de instrumentos para fortalecer la cohesión social y promover la inclusión social entre la población, tal como lo conciben la Observación General y la Resolución, analizadas supra, lo que resulta de la mayor importancia política en tiempos de crisis económico-social. En efecto, una solidaridad insuficiente implica que la seguridad social realiza menos de lo necesario para ambos efectos, mientras que una solidaridad suficiente es la que otorga una protección social efectiva a la población. Esto último supone que el Estado desempeñe un papel de administrador, regulador y fiscalizador en materia de seguridad social, reconociendo al mismo tiempo la colaboración activa de toda la sociedad. Lamentablemente, la CPR es silente sobre este principio y el régimen jurídico analizado no lo recepciona suficientemente, pese a la jurisprudencia constitucional reciente, citada supra. Por el contrario, la CPR y el régimen jurídico de la seguridad social chileno enfatizan más el principio de subsidiariedad, el que es leído en clave neoliberal y afecta al Estado más de lo necesario para desempeñar una función protectora de la población, con serio compromiso de la dignidad y desarrollo personal de las personas.

En gran medida, este estado de cosas proviene del hecho que el Estado chileno ha perseverado en una forma de seguridad social condicionada profundamente por el contexto económico y político de las últimas décadas. En consecuencia, los déficits normativos apuntados provienen de decisiones políticas y económicas relacionadas con el régimen socio-económico instaurado por la CPR y los resultados finales del sistema de seguridad social son bastante inciertos en términos de bienestar colectivo y promoción de los derechos fundamentales, a pesar de los avances de los últimos años.

\section{Referencias}

Arellano, O. P. (2012). Universalismo e individualismo en el derecho chileno de pensiones. Santiago: Librotecnia.

Asociación AFP Chile. (2015). El Sistema AFP. Retirado de http://www.aafp.cl/sistema-de-afp

Barraza, M. (2015, enero 11). El proyecto de AFP estatal "por lo pronto" no mejoraría las pensiones de los chilenos. Retirado de http://radio.uchile.cl/2015/01/11/marcos-barraza-el-proyecto-de-afp-estatal-no-mejoraria-las-pensiones-de-los-chilenos

Benavides, P. S. \& Jones, I. J. (2012, diciembre). Sistema de Pensiones y otros Beneficios Pecuniarios de las Fuerzas Armadas y de Orden y Seguridad Pública y Gendarmería de Chile: Situación Actual y Proyecciones Fiscales 2012-2050. Santiago: Estudios de Finanzas Públicas. Retirado de http://www.dipres. gob.cl/594/articles-98744_doc_pdf.pdf

Bertelsen, R. R. (1987). Tendencias en el reconocimiento y protección constitucional de los derechos en Chile. Revista Chilena de Derecho, 14(1), 49-62. 
Bowen, H. A. (1974). Introducción a la Seguridad Social. Santiago: Nueva Universidad.

Carta de la Organización de Estados Americanos, de 1948. Retirado de http://www.oas.org/dil/ esp/tratados_A-41_Carta_de_la_Organizacion_de_los_Estados_Americanos.htm

Constitución, convenios, resoluciones y recomendaciones de la Organización Internacional del Trabajo. Retirado de http://www.ilo.org/dyn/normlex/es/f? p=NORMLEXPUB:12020:0::NO:::

Constitución Política de 1925. Retirado de http://www.leychile.cl/Navegar?idNorma=131386

Constitución Política de 1980. Retirado de https://www.leychile.cl/Navegar?.idNorma $=242302$

Convención Internacional sobre la Eliminación de todas las Formas de Discriminación Racial, de 1965. Retirado de http://www.ohchr.org/SP/Professionallnterest/Pages/CERD.aspx

Convención sobre Derechos del Niño, de 1989. Retirado de http://www.un.org/es/events/childrenday/pdf/derechos.pdf

Convención sobre la Eliminación de todas las Formas de Discriminación contra la Mujer, de 1979. Retirado de http://www.un.org/womenwatch/daw/cedaw/text/sconvention.htm

Comité de Derechos Económicos, Sociales y Culturales. (2008). Observación General N 19. El derecho a la seguridad social (artículo 9). Ginebra: Consejo Económico y Social, 2007 Retirado de http:// conf-dts1.unog.ch/1\%20SPA/Tradutek/Derechos_hum_Base/CESCR/00_1_obs_grales_Cte\%20 Dchos\%20Ec\%20Soc\%20Cult.html\#GEN19

Consejo Asesor para la Reforma Previsional. (2006). El Derecho a una Vida Digna en la Vejez. Informe del Consejo Asesor Presidencial para la Reforma del Sistema Previsional. Santiago. Retirado de http:// www.comisionpensiones.cl/? wpfb_dl $=215$

Cumplido, F. C. (2003). La reforma constitucional de 1989 al inciso $2^{\circ}$ del artículo $5^{\circ}$ de la Constitución: sentido y alcance de la reforma. Doctrina y jurisprudencia. Ius et Praxis, 9(1), 365-374.

Dahl, R. A (2008). La igualdad política. Buenos Aires: Fondo de Cultura Económica.

Declaración Americana de los Derechos y Deberes del Hombre, de 1948. Retirado de http://www. oas.org/es/cidh/mandato/Basicos/declaracion.asp

Declaración Universal de los Derechos Humanos, de 1948. Retirado de http://www.un.org/es/documents/udhr

Excma. Corte Suprema de Justicia de Chile. Retirado de www.pjud.cl

Fernández, B. M. (2013). La Constitución contra sí misma. Precariedad de derechos y Reforma Constitucional en Chile. Santiago: Legal Publishing Thomson Reuters.

Galdámez, L. Z. (2014). El valor asignado por la jurisprudencia del Tribunal Constitucional a la jurisprudencia de la Corte Interamericana de Derechos Humanos. Estudios Constitucionales, 12(1), 329-364.

Grzetich, L. A. (2005). Derecho de la Seguridad Social (Vol. 1). Montevideo: Fundación de Cultura Universitaria. 
Gumucio, J. R. S. (2009). Descripción del sistema chileno de seguridad desde la perspectiva del Convenio Núm. 102, de 1952, de la OIT. Revista Latinoamericana de Derecho Social, (8), 131-170.

Humeres, H. N. (2005). Derecho del Trabajo y de la Seguridad Social (Tomo III). Santiago: Jurídica de Chile.

Iltma. Corte de Apelaciones de Rancagua, Chile. Retirado de www.pjud.cl

Lanata, G. F. (2001). Manual de Legislación Previsional. Santiago: Jurídica ConoSur.

Mendoza, L. (2015, julio 9). Turbulencia en los mercados: Dólar alto podría salvar rentabilidad de las AFP. 46\% en el extranjero. La Segunda, p. 21. Retirado de http://impresa.lasegunda. com/2015/07/09/A/VK2NPVON

Nogueira, H. A. (2008). Derechos fundamentales y garantías constitucionales (Tomo III). Santiago: Librotecnia.

Nogueira, H. A. (2008). El bloque constitucional de derechos: La concordancia del derecho internacional y del derecho constitucional en el aseguramiento y garantía de los derechos fundamentales en América Latina. En M. H. Llanos, Estudios de Derecho Internacional. Libro homenaje al profesor Santiago Benadava (pp. 265-304). Santiago: Librotecnia.

Novoa, P. F. (1977). Derecho de la Seguridad Social. Santiago: Jurídica de Chile.

Obando, I. C. (2012). El derecho a la seguridad social en el constitucionalismo chileno: un continente en busca de su contenido. Estudios Constitucionales, 10(1), 289-338.

Oficina del Alto Comisionado de las Naciones Unidas para los Derechos Humanos. (2004). Compilación de observaciones finales del Comité de Derechos Económicos, Sociales y Culturales sobre países de América Latina y el Caribe (1989-2004). Santiago: Alto Comisionado de las Naciones Unidas para los Derechos Humanos Representación Regional para América Latina y el Caribe; Comisión Económica para América Latina y el Caribe (CEPAL). Retirado de http://www.ohchr.org/Documents/ HRBodies/CESCR/CESCRCompilacionGC_sp.pdf

Pacto Internacional de Derechos Económicos, Sociales y Culturales, de 1966. Retirado de http:// www.ohchr.org/SP/ProfessionalInterest/Pages/CESCR.aspx

Plataforma Interamericana de Derechos Humanos, Democracia y Desarrollo (PIDHDD). (2003). Derecho humano a la seguridad social. Apuntes y reflexiones desde la experiencia de América Latina. Caracas. Retirado de http://caf.msinfo.info/bases/biblo/texto/bb-1557.pdf

Protocolo Adicional a la Convención Americana sobre Derechos Humanos en materia de Derechos Económicos, Sociales y Culturales, de 1988. Retirado de http://www.oas.org/juridico/spanish/tratados/a-52.html

Sentencias judiciales

Ríos, L. A. (1998). Jerarquía normativa de los tratados sobre derechos humanos. Gaceta Jurídica, (215): 7-14.

Tribunal Constitucional de Chile. Retirado de http://www.tribunalconstitucional.cl/wp/ 
Ivan Obando Camino

Vergara, P. (1985). Auge y Caida del Neoliberalismo en Chile. Santiago: Flacso.

Zúñiga, F. U. (2008, enero/agosto). Derechos humanos en la jurisprudencia del Tribunal Constitucional chileno. Apostillas sobre tratados y constitución. Revista de Derecho Político, (71-72), 789-827. 